\title{
PRINCIPIOS DE PSICOFARMACOLOGÍA: UNA INTRODUCCIÓN
}

\section{PRINCIPLES OF PSYCHOPHARMACOLOGY: AN INTRODUCTION}

\section{Julio TORALES ${ }^{1}$, Andrés ARCE ${ }^{2}$.}

${ }^{1}$ Profesor Asistente de Psiquiatría, Facultad de Ciencias Médicas, Universidad Nacional de Asunción, San Lorenzo - Paraguay.

${ }^{2}$ Profesor Titular y Jefe de Cátedra de Psiquiatría, Facultad de Ciencias Médicas, Universidad Nacional de Asunción, San Lorenzo - Paraguay.

Cómo citar este artículo: Torales J, Arce A. Principios de Psicofarmacología: una introducción. Medicina Clínica y Social. 2017;1(1): 54-99.

\section{RESUMEN}

La psicofarmacología puede definirse como una disciplina científica centrada en el estudio de los fármacos que modifican el comportamiento y la función mental a través de su acción sobre el sistema neuroendocrino. Se trata de un campo del saber que tiene un marcado carácter multidisciplinario, al agrupar el interés que comparten médicos psiquiatras, generales y neurólogos, farmacólogos, y bioquímicos por el análisis de las sustancias que actúan modificando las funciones del sistema nervioso, y que se manifiestan en la conducta de los individuos. A lo largo de este artículo se abordará un análisis conceptual de la psicofarmacología y se revisarán algunos de los principales acontecimientos históricos que han marcado el curso de la disciplina, así como los principios básicos de la neurobiología y neuroquímica y los aspectos generales de la farmacocinética y la farmacodinámica de los psicofármacos. Se hará también alusión a la psicofarmacología de poblaciones en situaciones vitales específicas (niños y adolescentes, adultos mayores y mujeres embarazadas) y a la psicofarmacología de pacientes con enfermedad renal o hepática. Por último, se esbozarán algunas líneas acerca del papel de la genética en la psiquiatría y la psicofarmacología.

Palabras clave: Psicofarmacología; Neurobiología; Neuroquímica; Neurotransmisión; Psicofármacos.

\section{ABSTRACT}

Psychopharmacology can be defined as a scientific discipline focused on the study of drugs that modify behavior and mental function through their action on the neuroendocrine system. It is a field of knowledge that has a marked multidisciplinary character, by grouping the interest shared by psychiatrists, general physicians and neurologists, pharmacologists, and biochemists for the analysis of substances that act by modifying the functions of the nervous system, and which manifest themselves in the individuals' behavior. Throughout this article, we will address a conceptual analysis of psychopharmacology and will review some of the major historical events that have marked the course of the discipline, as well as the basic principles of neurobiology and neurochemistry and the general aspects of pharmacokinetics and pharmacodynamics of psychotropic drugs. Allusion will also be made to the psychopharmacology of populations in specific life situations (children and adolescents, older adults and pregnant women) and the psychopharmacology of patients with renal or hepatic disease. Finally, some lines will be outlined about the role of genetics in psychiatry and psychopharmacology.

Keywords: Psychopharmacology; Neurobiology; Neurochemistry; Neurotransmission; Psychotropic drugs. 


\section{INTRODUCCIÓN}

La esquizofrenia, la depresión, la demencia y otros trastornos mentales, neurológicos y relacionados con el uso de sustancias constituyen el 13\% de la carga mundial de enfermedades, superando a las afecciones cardiovasculares y al cáncer. Por ejemplo, la depresión por sí sola es la tercera contribuyente a la carga mundial de enfermedades; mientras que cada siete segundos alguien desarrolla demencia alrededor del mundo, costando a la humanidad hasta 609 millones de dólares por año, sin contar el extremo sufrimiento que genera en los pacientes, su familia y la comunidad. Asimismo, para el año 2020, se estima que 1,5 millones de personas morirán cada año debido al suicidio, y entre 15 y 30 millones lo habrán intentando (1-3).

La ausencia de curas para muchos de los trastornos mentales y la escasez de intervenciones preventivas para muchos otros, en parte reflejan una comprensión aún limitada del cerebro y sus mecanismos moleculares y celulares. Por su parte, en las patologías que cuentan con tratamientos eficaces, los mismos no siempre están disponibles para las personas y comunidades más necesitadas (3). La desigual distribución de los recursos humanos y otros (entre y dentro de los países) debilita aún más el acceso a los servicios de salud mental: por ejemplo, la región europea de la Organización Mundial de la Salud tiene 200 veces más el número de psiquiatras que África. En todos los países del mundo, la inversión en investigación (fundamental en la prevención y tratamiento de los trastornos mentales) es desproporcionadamente baja en relación a la carga producida por estas enfermedades $(4,5)$.

Por todo lo expuesto, se hace necesario optimizar el reconocimiento y el tratamiento de los trastornos mentales, principalmente en aquellos lugares donde se evidencian limitaciones en la disponibilidad tanto de médicos psiquiatras y otros profesionales de la salud mental, como de recursos terapéuticos. En este contexto, una sólida formación en psicofarmacología es clave en la práctica clínica diaria, no solo para el médico psiquiatra, sino también para el médico de familia y de atención primaria de la salud, para el especialista en medicina interna, para el geriatra y para el neurólogo, profesionales todos involucrados en el tratamiento de los trastornos mentales, en mayor o menor grado. El correcto conocimiento de los psicofármacos, destinados a curar o aliviar los trastornos mentales, es crucial para asegurar que los mismos sean utilizados de manera efectiva y segura (6).

Aunque la medicación juega un papel que fluctúa entre lo prioritario y lo adyuvante en cada uno de los trastornos mentales, tanto los pacientes como sus familias tienen derecho a esperar que todos los médicos estén al día con sus conocimientos sobre el rol de los psicofármacos. Se hace necesario destacar que la psicofarmacología de ninguna manera disminuye la contribución de los enfoques psicológicos y sociales en el tratamiento de los trastornos mentales, ni la importancia de la relación entre el médico y el paciente. De hecho, en ese sentido se necesitan habilidades específicas para asegurar el consentimiento informado y la promoción de la adherencia al tratamiento (7).

Por muchos años se ha suscitado un debate en la psiquiatría acerca de la etiología y el tratamiento de los trastornos mentales. Dos campos opuestos emergieron: la psiquiatría biológica, que esgrime que los trastornos psiquiátricos tienen una base orgánica; y la psiquiatría orientada psicológicamente (representada mejor por el movimiento psicodinámico), que se 
enfoca en el rol de los estresores emocionales, traumas infantiles, problemas interpersonales y conflictos intrapsíquicos como agentes causales del desarrollo de sintomatología psiquiátrica (7). Estos polos todavía existen hoy en día; no obstante, y afortunadamente, en los últimos años se ha logrado desarrollar una visión que engloba tanto a los factores biológicos como a los psicológicos y sociales en la etiología y tratamiento de los trastornos mentales.

Se debe tener en cuenta que el tratamiento de las afecciones mentales se encuentra inserto en la complejidad propia de la mente. Su manejo integral implica desarrollar una visión biopsicosocial, que se funda en el reconocimiento del cuerpo como biología y percepción, junto a la intersubjetividad que se constituye en la relación médico paciente y la funcionalidad psicosocial. Todo lo anterior es necesario para que los procesos y resultados sean monitorizados y comprobados en indicadores (evidencias) multidimensionales, desde parámetros biológicos, cognitivos, afectivos y conductuales.

En el caso específico de la psicofarmacología, un mayor énfasis en su discernimiento se basa en la necesidad de conocer acabadamente el potencial que tienen los psicofármacos de causar daños graves. Asimismo, un buen médico, psiquiatra o no, debe poseer capacidades no sólo para cumplir con guías de tratamiento, sino que también, y, sobre todo, para desarrollar competencias en el uso de psicofármacos para casos complejos (incluyendo combinaciones y usos no validados), para casos en los que no existan directrices o donde no se las pueda seguir. Por último, la posibilidad de litigios civiles y penales relacionados al uso de la medicación (errores de omisión y de acción) no debe ser pasada por alto $(1,8)$.

La evidencia de que los psicofármacos son beneficiosos cuando se utilizan de manera correcta y para las indicaciones adecuadas es abrumadora e inequívoca, por lo que la psicofarmacología debe ser reafirmada como componente integral y significativo de lo que todos los médicos deben conocer. Un mejor enfoque en el entrenamiento, práctico y basado en la evidencia, de la psicofarmacología beneficiará a los pacientes al mejorar los estándares en el uso racional y eficaz de los psicofármacos.

La psicofarmacología puede definirse como una disciplina científica centrada en el estudio de los fármacos que modifican el comportamiento y la función mental a través de su acción sobre el sistema neuroendocrino. Se trata de un campo del saber que tiene un marcado carácter multidisciplinario, al agrupar el interés que comparten médicos psiquiatras, generales y neurólogos, farmacólogos, y bioquímicos por el análisis de las sustancias que actúan modificando las funciones del sistema nervioso, y que se manifiestan en la conducta de los individuos $(9,10)$. A lo largo de este artículo se abordará un análisis conceptual de la psicofarmacología y se revisarán algunos de los principales acontecimientos históricos que han marcado el curso de la disciplina (en los siglos XIX y XX), así como los principios básicos de la neurobiología y neurotransmisión química y los aspectos generales de la farmacocinética y la farmacodinámica de los psicofármacos. Se hará también alusión a la psicofarmacología de poblaciones en situaciones vitales específicas (niños y adolescentes, adultos mayores y mujeres embarazadas) y a la psicofarmacología de pacientes con enfermedad renal o hepática. Por último, a manera de conclusión, se esbozarán algunas líneas acerca del promisorio papel de la genética en la psiquiatría y la psicofarmacología. 


\section{HISTORIA DE LA PSICOFARMACOLOGÍA}

A lo largo de la historia de la psicofarmacología se ha observado que muchos de sus descubrimientos no obedecen a un desarrollo lógico, puesto que la etiología de muchos trastornos psiquiátricos aún sigue sin conocerse: solo cierto número de hipótesis patogénicas, somáticas o psicológicas han sido formuladas. De tal modo, la causalidad de estos trastornos debe interpretarse como factorial. Así, el tratamiento psicofarmacológico no constituye más que una parte, que incluye igualmente una dimensión psicológica y social (11).

Aunque todavía no existe un acuerdo generalizado a la hora de determinar qué acontecimiento marcó el inicio de la psicofarmacología moderna, existen algunos hitos importantes que son considerados los cimientos en los que se basa esta ciencia médica (10):

- Joseph Moureau de Tours: En la primera mitad del siglo XIX contribuyó con sus estudios sobre el hachís a dar unos primeros aportes psicofarmacológicos planificados científicamente;

- Emil Kraepelin: Estudiante de Wilhelm Maximilian Wundt, es también considerado fundador de la psicofarmacología, gracias a sus experimentos centrados en los efectos de diferentes sustancias psicoactivas y venenos sobre procesos intelectuales elementales; $y$,

- D.I. Match: Sus investigaciones, muy similares a las de Kraepelin, estaban basadas en estudios científicos de las acciones conductuales de los fármacos.

No obstante, para otros autores, la psicofarmacología se inicia gracias a una serie de observaciones clínicas y descubrimientos farmacológicos que se sucedieron a en el siglo XX (en las décadas de los años cuarenta y cincuenta), entre los que destacan:

- Los trabajos sobre la LSD-25 (dietilamida de ácido lisérgico, LSD-25 o simplemente LSD, molécula conocida coloquialmente como "ácido") realizados por Albert Hofmann y publicados en 1943; $y$,

- El descubrimiento de los efectos antipsicóticos de la clorpromazina por Delay y Deniker en 1952.

La posibilidad de modificar la psique mediante la administración de agentes químicos (en el primer caso), y de controlar procesos psicopatológicos mediante el uso de fármacos (en el segundo), abrió posibilidades insospechadas para la investigación cerebral y la práctica clínica, muchas de las cuales ejercen aún su influencia en la psicofarmacología actual.

\section{Surgimiento de la psicofarmacología moderna}

Es preciso destacar los avances que se suceden en los siglos XIX y XX en el campo de la psiquiatría, que se asienta de forma definitiva como especialidad médica con entidad propia. Tras el fracaso de los tratamientos utilizados en la época, en el siglo XIX se asiste a un cambio de mentalidad en virtud del cual el estudio de las psicopatologías es abordado ahora desde una perspectiva positivista y humanista, que asimila la fisiología de la mente a las funciones del cerebro $(9,12)$. 
De este modo, dado que la enfermedad mental debía tener necesariamente un correlato en alguna alteración cerebral, se hace posible la implantación de terapias que van dirigidas a la manipulación directa de dicha alteración, a pesar de que a menudo ésta no era conocida de forma precisa. Las alternativas terapéuticas disponibles no eran, sin embargo, muy innovadoras, y así, en la práctica de los "manicomios" se siguieron aplicando procedimientos tradicionales como la inmovilización, la silla giratoria, la inducción de náuseas y vómitos como terapia antiagitación, e incluso las duchas frías y el castigo físico (13). Asimismo, durante la mayor parte del siglo anterior había tenido lugar una progresiva implantación de métodos terapéuticos de carácter sedante, enfocados a calmar a personas agitadas o agresivas. Una forma extrema de tratamiento fue conocida como la "cura de sueño" o narcosis continua, que buscaba mantener durante días al paciente en estado de sueño permanente mediante una narcosis inducida con la oportuna medicación (por ejemplo, con barbitúricos) (14).

Al margen de la narcosisterapia, las conocidas como terapias de choque ocuparon igualmente un lugar importante en los tratamientos de la época. Por ejemplo, Manfred Sakel introdujo (en 1933) el tratamiento de choque insulínico, tras descubrir de forma casual que una dosis excesiva de insulina ingerida por un enfermo mental diabético le había provocado un estado de coma con convulsiones que había mejorado las condiciones de su estado psicótico. Este tratamiento fue apartado de la práctica psiquiátrica tras la introducción de la terapia electroconvulsiva, desarrollada por Cerletti y Bini en 1938, y que rápidamente se convertiría en el tratamiento de elección en la esquizofrenia. El auge de este tratamiento (y de otros, como la lobotomía prefrontal) sólo empezó a declinar tras el descubrimiento de los primeros agentes antipsicóticos (9), si bien la terapia electroconvulsiva continúa empleándose hoy en día.

A pesar de que los tratamientos descriptos sucintamente más arriba mostraron efectos poco consistentes en el alivio de las distintas psicopatologías, sin duda contribuyeron al crecimiento de un cierto optimismo terapéutico convencido de que la cura de dichas enfermedades estaba cerca. Este cambio de paradigma tuvo dos consecuencias fundamentales: 1. Por un lado, propició una profunda metamorfosis en el funcionamiento de los hospitales, contribuyendo a un tratamiento más humanitario de los enfermos y a una mejoría clara en su pronóstico; $y, 2$. Por otro, facilitó la acogida positiva que prestaron muchos clínicos a los fármacos que se desarrollaron a partir de la década de los años cincuenta del siglo XX, y que supondrían un claro punto de inflexión en el desarrollo de la clínica psiquiátrica.

\section{Hallazgos neuroquímicos}

Uno de los hitos neurocientíficos más importantes del siglo XX fue el descubrimiento de los neurotransmisores. Durante la segunda mitad del siglo XIX, dos eran las teorías que predominaban sobre la histofisiología del sistema nervioso $(9,10)$ :

- La teoría reticular que asumía que las neuronas estaban interconectadas a través de puentes protoplasmáticos y, por tanto, no podían actuar de forma independiente; $y$,

- La teoría celular, por el contrario, consideraba que las neuronas estaban separadas entre sí y actuaban como unidades funcionalmente autónomas. El trabajo realizado por Santiago Ramón y Cajal hizo que esta teoría fuera finalmente aceptada, a inicios del siglo XX. 
No obstante, la aceptación de la teoría celular abrió nuevos interrogantes, dado que implicaba, necesariamente, la existencia de un mecanismo de comunicación interneuronal. Por ello, nuevamente, dos posicionamientos surgieron: uno que defendía la naturaleza eléctrica de ese mecanismo, y otro que abogaba por una naturaleza química.

Abogaron por la hipótesis química Elliott (que comprobó que la adrenalina imitaba los efectos de la estimulación del sistema nervioso simpático), Loewi (que descubrió que la sustancia química "vagusstoff", conocida luego como acetilcolina, era la responsable de generar bradicardia en corazones animales) y Dale (quien demostró que la acetilcolina actuaba como neurotransmisor en las sinapsis de los ganglios autonómicos y en la unión neuromuscular). A pesar de estas primeras evidencias, los círculos científicos se mantuvieron firmes en que la comunicación interneuronal en el cerebro era eminentemente eléctrica y, además, que los trabajos de Elliott, Loewi y Dale se centraban en el sistema nervioso periférico, donde la neurotransmisión química era ampliamente aceptada (10).

En vista a lo anterior, los esfuerzos de los investigadores se dirigieron a la búsqueda de sustancias transmisoras en áreas cerebrales específicas. Las primeras en descubrirse fueron la serotonina y la dopamina. La serotonina fue identificada de forma independiente por Erspamer en Italia y por Page, en Estados Unidos de América. Por su parte, la dopamina fue hallada por Carlsson, Lindqvist, Magnusson y Waldeck, quienes descubrieron concentraciones de dopamina en el cerebro de conejos muy superiores a las esperables si ésta actuara como mero precursor de la noradrenalina, como se creía en la época. Poco después se conocería la distribución regional de este neurotransmisor en el cerebro humano, y surgirían también las primeras evidencias sobre la implicación de la dopamina en la enfermedad de Parkinson. Finalmente, el campo de la neuroquímica cerebral sufrió una transformación radical, coincidiendo con los primeros estudios dirigidos a esclarecer el mecanismo de acción de los psicofármacos, que estaban demostrando efectividad en el ámbito clínico. Esta nueva línea de investigación despejó las dudas existentes sobre la neurotransmisión química cerebral, y condujo a la identificación de la mayoría de los neurotransmisores conocidos en la actualidad $(10,11)$.

\section{Descubrimiento de los psicofármacos}

Como se mencionó previamente, el descubrimiento de los efectos antipsicóticos de la clorpromazina es considerado por algunos autores como el hito inicial de la psicofarmacología moderna (otros investigadores añaden también a la introducción del litio, como sustancia terapéutica en psiquiatría en 1949, como otro de los hitos de inicio de esta disciplina). No obstante, es de destacar que la eficacia de estos fármacos se descubrió por casualidad o partiendo de hipótesis equivocadas, fenómeno que se repitió en el desarrollo de otros psicofármacos, introducidos con unas expectativas que poco tienen que ver con su uso posterior (Tabla 1) $(10,14,15)$. 


\section{TABLA 1. CASUALIDAD EN EL MUNDO DE LA PSICOFARMACOLOGÍA}

- La acción profiláctica del litio en la manía fue descubierta de forma accidental.

- La clorpromazina se probó inicialmente como sedativo, descubriéndose su acción antipsicótica al administrarla a pacientes con esquizofrenia.

- La iproniazida, primer inhibidor de la monoamino-oxidasa (IMAO), se ensayó como antituberculoso. Al ver que los pacientes tenían una mejoría del estado de ánimo se concluyó que la misma poseía acción antidepresiva.

- La imipramina, primer tricíclico, se utilizó inicialmente como antipsicótico.

- Se creía que la estructura química de la clozapina haría de ella un buen antidepresivo.

- La estabilización del estado de ánimo de pacientes epilépticos tratados con carbamazepina, dio inicio a la utilización de antiepilépticos en los trastornos del humor.

De hecho, hasta la síntesis de la fluoxetina a inicios de la década de 1970 no hubo una teoría capaz de alumbrar un psicofármaco (15).

Pese a esta "endeble" base científica original, en los más de 60 años transcurridos desde el descubrimiento de la clorpromazina se ha producido un gran progreso científico y técnico en el que la psicofarmacología ha sido la fuerza impulsora que ha permitido el avance de la llamada psiquiatría biológica. El desarrollo de las teorías neurobiológicas clásicas sobre la depresión (monoaminérgica) o la esquizofrenia (dopaminérgica) a partir de presuntos mecanismos de acción de los fármacos eficaces en estas patologías ha demostrado como la psicofarmacología ha modelado a la psiquiatría biológica y a la práctica clínica asistencial (15).

Existen un sinnúmero de hechos que han marcado a la psicofarmacología de la segunda mitad del siglo XX, por ejemplo, desde la publicación del primer "Tratado de Psicofarmacología" de Boor (en 1956) hasta la aprobación de la lamotrigina como estabilizante del ánimo (en 2003). Se recomienda al lector interesado en conocer más a fondo éstos y otros hechos históricos de la ciencia psicofarmacológica que consulte el "Tratado de Psicofarmacología" de Salazar, Peralta y Pastor (Editorial Médica Panamericana, 2010) y el libro "Historia de la Neuropsicofarmacología” de López-Muñoz y Álamo (Ediciones Eurobook, 1998) $(16,17)$.

\section{DEFINICIÓN ACTUAL DE LA PSICOFARMACOLOGÍA}

Como se mencionó en la introducción del presente artículo, la psicofarmacología puede definirse como una disciplina científica centrada en el estudio de los fármacos que modifican el comportamiento y la función mental a través de su acción sobre el sistema neuroendocrino $(9,10)$. Esta perspectiva destaca el interés de la psicofarmacología en el estudio de las interacciones entre los fármacos, el sistema nervioso, y el comportamiento normal y patológico.

Sin embargo, se pueden encontrar otras múltiples matizaciones en las conceptualizaciones actuales de la psicofarmacología, destacando ya sea su carácter básico o aplicado. En este sentido, se resaltan aquellas definiciones que dan un importante y equiparable valor al estudio de los sustratos neurales y a los mecanismos de acción de un determinado fármaco:

- Stahl: Afirma que la psicofarmacología se orienta al descubrimiento de fármacos y a la comprensión de sus acciones en el sistema nervioso central (18); 
- Bloom: Destaca como uno de los principales objetivos de la psicofarmacología el empleo de fármacos para descubrir los mecanismos que operan en el sistema nervioso central y las bases biológicas de procesos mentales complejos (19); y, finalmente

- Pinel: Enfatiza en que la psicofarmacología tiene su interés en la manipulación neural y de la conducta a través de fármacos (20).

La variedad de definiciones que pueden encontrarse en torno al término psicofarmacología no hace más que poner de manifiesto su naturaleza multidisciplinaria y la riqueza de contenidos que aporta al campo de la neurociencia, en el que se encuentra adscripta (10).

Por su parte, tres términos generales e intercambiables entre sí describen a los fármacos utilizados en el tratamiento de los trastornos psiquiátricos: psicotrópicos, psicofármacos y fármacos psicoterapéuticos (21). Tradicionalmente, los psicofármacos se han dividido en 5 categorías: 1. Antipsicóticos o neurolépticos, para tratar la psicosis; 2. Antidepresivos, para tratar la depresión; 3. Estabilizantes del ánimo o timorreguladores, para tratar el trastorno bipolar; 4. Ansiolíticos, para tratar la ansiedad (y que también son efectivos como hipnóticos); $y, 5$. Antidemenciales, para tratar la demencia (1, 2, 21). Sin embargo, estas distinciones categóricas resultan cada día menos válidas por las razones que se exponen en la tabla 2 $(2,21)$.

\section{TABLA 2. EL POR QUÉ DE LA INVALIDEZ DE LOS DOMINIOS CATEGORIALES EN PSICOFARMACOLOGÍA}

- Muchos fármacos de una clase se utilizan para tratar trastornos asignados previamente a otra clase (por ejemplo, los antidepresivos se utilizan hoy en día para tratar un amplio abanico de trastornos de ansiedad).

- Los fármacos que se introdujeron para tratar la esquizofrenia, como los antagonistas de serotonina y dopamina (antipsicóticos atípicos), también están indicados para el tratamiento del trastorno bipolar y tienen cierta actividad antidepresiva.

- Los fármacos de 4 de las 5 categorías citadas arriba (menos los antidemenciales) se utilizan para tratar síntomas y trastornos como el insomnio, los trastornos de la conducta alimentaria y los trastornos del control de los impulsos.

- La clonidina, el propranolol, el verapamilo, el modafinilo y la gabapentina son fármacos que sirven para tratar numerosos trastornos psiquiátricos, más no resulta fácil clasificarlos en ninguna de las 5 categorías.

Más adelante en este artículo se presenta una propuesta de clasificación de los psicofármacos, pero antes se exponen los fundamentos que hacen a la neurobiología y a la neurotransmisión química, pilares del entendimiento actual de la psicofarmacología.

\section{FUNDAMENTOS DE NEUROBIOLOGÍA Y DE NEUROTRANSMISIÓN QUÍMICA}

La unidad estructural básica del sistema nervioso es la neurona. Ésta es una célula altamente especializada, con capacidad de recibir, procesar y enviar información, tanto del medio interno como del externo (22). 
La respuesta de una neurona ante estímulos diversos se manifiesta por la génesis de un impulso nervioso de tipo eléctrico. La neurona en reposo se encuentra polarizada, es decir, existe una carga intracelular negativa $(-70 \mathrm{mV})$ con respecto al exterior de la membrana. Este potencial de reposo se debe a la existencia de una concentración de iones $\mathrm{K}^{+} 40$ veces superior en el exterior de la célula que en su interior. Estos gradientes de concentración a uno y otro lado de la membrana son mantenidos por la presencia de bombas iónicas asociadas a la membrana y dependientes de la energía proporcionada por el adenosintrifosfato (ATP), que transportan de forma activa las partículas con carga eléctrica.

La diferencia de carga eléctrica proporciona a la neurona una energía potencial que es liberada cuando se estimula, gracias a la entrada brusca de $\mathrm{Na}^{+}$. La rápida entrada de estas cargas positivas hace que el valor de la carga negativa existente en el interior de la neurona, en la región estimulada, disminuya rápidamente hacia la positividad (despolarización de la membrana), iniciándose un impulso nervioso o potencial de acción que transmite información a lo largo de la neurona. El $\mathrm{Ca}^{+2}$ también ingresa a la neurona, como consecuencia del potencial de acción, y es el responsable de generar procesos de liberación de neurotransmisores. Luego, la neurona recupera su estado de reposo gracias a la salida de $\mathrm{K}^{+}$al exterior (repolarización de la membrana).

El orden y dirección correcta del flujo iónico de una neurona que experimenta un potencial de acción es, por tanto, $\mathrm{Na}^{+}$dentro, $\mathrm{Ca}^{+2}$ dentro, $\mathrm{K}^{+}$fuera.

\section{Comunicación entre neuronas}

La comunicación interneuronal tiene lugar en las sinapsis, zona de contacto que se establece entre dos neuronas con la finalidad de transmitir información. Las neuronas están organizadas de tal manera que pueden enviar información sináptica a otra neurona (función presináptica de la neurona), así como recibir dicha información (función postsináptica de la neurona).

Cuando la neurona ejerce una función presináptica, es decir, envía información a otra neurona, lo hace a través de un largo axón ramificado en fibras terminales preparadas para establecer el contacto sináptico con otras neuronas. Por otra parte, cuando la neurona ejerce una función postsináptica puede recibir información a través de sus dendritas, de su axón o de su cuerpo celular (soma).

La tabla 3 esquematiza los tipos de sinapsis que pueden establecer entre neuronas, según su naturaleza eléctrica o química $(9,10)$.

\section{TABLA 3. TIPOS DE SINAPSIS SEGÚN SU NATURALEZA}

En este tipo de sinapsis, ambas neuronas se encuentran casi en total contacto físico, por lo que la sinapsis ocurre entre sus membranas celulares. La membra-

Sinapsis eléctricas na presináptica libera, a través de canales iónicos, iones y moléculas de pequeño tamaño de una célula a otra. Esta zona de íntimo contacto entre neuronas, donde se da la liberación de iones, recibe la denominación de unión hendida. 
Aquí la comunicación interneuronal se lleva a cabo por la liberación de un neurotransmisor desde los botones presinápticos hasta los botones postsinápticos de la neurona que recibe la información. Se debe recordar que la liberación del neurotransmisor no se hace directamente al botón postsináptico, sino que se libera en un espacio extracelular denominado espacio o hendidura sináptica.

Podría decirse que la psicofarmacología moderna es una historia basada en la neurotransmisión química (18). Para comprender las acciones de los fármacos sobre el cerebro, asimilar el impacto de las enfermedades sobre el sistema nervioso central y para interpretar las consecuencias conductuales de los psicotrópicos se debe adquirir un buen conocimiento de los principios de la sinapsis y la neurotransmisión química.

Las sinapsis químicas se pueden clasificar obedeciendo a dos características esenciales de la neurona (10): 1. Según las zonas donde se envía y se recibe información; y, 2. Según el estado de activación de las neuronas.

Sinapsis químicas según la zona donde ocurra la comunicación:

- Sinapsis axodendríticas: Conexión que se da entre el axón de una neurona y las dendritas de otra. Es la forma más común en el sistema nervioso;

- Sinapsis axosomáticas: Conexión entre el axón de una neurona y el soma neuronal de otra;

- Sinapsis dendrodendríticas: Conexión entre dendritas de dos neuronas; y,

- Sinapsis axoaxónicas: Conexión entre axones de dos neuronas.

Sinapsis químicas según el estado de activación de las neuronas:

- Sinapsis tipo I: En las que se produce la activación de la neurona postsináptica. En este tipo de sinapsis generalmente se liberan neurotransmisores excitadores como el glutamato o la acetilcolina y son fundamentalmente axodendríticas; $y$,

- Sinapsis tipo II: En las que se produce la inactivación de la neurona postsináptica. En este tipo de sinapsis generalmente se suelen liberar neurotransmisores inhibidores como el ácido gamma-aminobutínico (GABA) y la glicina y son fundamentalmente axosomáticas.

Neurotransmisores, neuromoduladores, neurorreguladores, cotransmisores y neuropéptidos

Las sustancias liberadas en las hendiduras sinápticas, consideradas moléculas transmisoras, poseen algunas características comunes, entre ellas su presencia en la neurona presináptica, junto con todas las enzimas involucradas en su síntesis, y ser liberadas tras la estimulación de esta neurona. Además, deben actuar sobre receptores específicos. El transmisor, aplicado a la célula diana, debe producir efectos similares a los obtenidos tras la estimulación de la neurona presináptica y este efecto debe ser bloqueado por antagonistas específicos de estos 
receptores. El efecto finaliza por mecanismos enzimáticos que destruyen el transmisor, o por la rápida desaparición de éste de la hendidura sináptica, gracias a mecanismos de transporte que promueven su recaptación presináptica.

Las moléculas transmisoras pueden comportarse como neurotransmisores, neuromoduladores y neurorreguladores (22).

Un neurotransmisor es una biomolécula, sintetizada por las neuronas, que se vierte, a partir de vesículas existentes en la neurona presináptica, hacia la brecha sináptica y produce un cambio en el potencial eléctrico de la neurona postsináptica. Los neurotransmisores son, por tanto, las principales sustancias de las sinapsis. Así, los neurotransmisores provocan en el terminal postsináptico de la célula con la que están en contacto, cambios electrofisiológicos que se traducen en potenciales postsinápticos excitadores o inhibidores. Los neurotransmisores excitadores, como la acetilcolina, producen potenciales postsinápticos excitadores, generados por la entrada de $\mathrm{Na}^{+}$en la célula, que duran 5 milisegundos aproximadamente. Si el receptor postsináptico es estimulado por un neurotransmisor inhibidor, como el GABA o la glicina, se produce la entrada de iones $\mathrm{Cl}^{-}$en el interior de la célula, que provocan una hiperpolarización denominada potencial postsináptico inhibidor $(22,23)$.

Los neuromoduladores son moléculas liberadas en la sinapsis que, si bien no generan potenciales de acción, influyen y modifican la capacidad de respuesta generada por los neurotransmisores. Vale acotar que una misma sustancia puede comportarse como neurotransmisor o neuromodulador, en distintas zonas encefálicas $(10,23,24)$.

Por su parte, los neurorreguladores son sustancias originadas en células diferentes de las neuronas, que influyen en la excitabilidad de las células nerviosas. En el grupo de neurorreguladores se incluyen a las prostaglandinas, el óxido nítrico y esteroides que circulan por el sistema nervioso central (23).

Un cotransmisor es una sustancia química que coexiste en el mismo botón terminal con un neurotransmisor, y puede ser liberado junto con el mismo. El cotransmisor puede comportarse como un segundo neurotransmisor, o bien como un neuromodulador (10).

\section{Neurotransmisores}

Existe más de una docena de neurotransmisores (entre identificados y sospechados) en el cerebro humano. No obstante, seis son los sistemas de neurotransmisores sobre los que se dirigen los psicofármacos: 1. Serotonina; 2. Noradrenalina; 3. Dopamina; 4 . Acetilcolina; 5. Glutamato; y, 6. GABA.

\section{Serotonina}

Es una amina biogénica indolaminérgica, sintetizada fundamentalmente en los núcleos del rafe del tronco encefálico, desde donde se envían proyecciones que se distribuyen por diversas regiones del sistema nervioso central. Su síntesis depende de la recaptación activa de triptófano que posteriormente es metabolizado por la enzima triptófano-5-hidroxilasa, con- 
virtiéndose en 5- hidroxitriptófano. Este último, a su vez, es metabolizado por la descarboxilasa de aminoácidos aromáticos en 5-hidroxitriptamina (serotonina).

El núcleo del rafe dorsal se localiza en la porción ventral de la sustancia gris periacueductal, y contiene el mayor número de neuronas serotoninérgicas del cerebro (aproximadamente 165 mil). El núcleo del rafe medio se encuentra en la porción central de la protuberancia. Desde ambos núcleos, las neuronas serotoninérgicas establecen múltiples contactos con otras neuronas, modulando su respuesta, por ejemplo: 1 . Inhiben las neuronas noradrenérgicas del locus coeruleus y regulan el número y función de los receptores $\beta$-adrenérgicos; $y, 2$. Poseen receptores glucocorticoides que alteran la transcripción genética, siendo importantes en los mecanismos que modulan la respuesta al estrés (10).

Las proyecciones serotoninérgicas se distribuyen por el locus coeruleus, el giro dentado del hipocampo, el sistema límbico, hipotálamo, tálamo, núcleo estriado, neocorteza, cerebelo y médula espinal. Es de destacar que se han detectado altas concentraciones de serotonina en estructuras como el plexo mientérico, las plaquetas, la glándula tiroides y las células enterocromafines (25).

La serotonina tiene un rol importante en el control del ciclo sueño-vigilia, inducción del sueño REM y sueño de ondas lentas, inhibición de la actividad mnésica, aumento del umbral del dolor, humor alterado, regulación del apetito, de la conducta agresiva y sexual. La neurotransmisión serotoninérgica aparece afectada en la enfermedad de Alzheimer, enfermedad de Parkinson, en la depresión, el alcoholismo, el suicidio, la esquizofrenia, los trastornos de la personalidad, ansiedad, bulimia, obesidad y en el trastorno obsesivo compulsivo (10).

\section{Noradrenalina}

Catecolamina sintetizada en el locus coeruleus, bulbo raquídeo y protuberancia (núcleo motor del vago y tracto solitario). La noradrenalina surge de la transformación de la dopamina por acción de la enzima $\beta$-hidroxilasa en el interior de las vesículas presinápticas. Las proyecciones noradrenérgicas se distribuyen por el núcleo supraóptico, núcleos periventriculares del hipotálamo, tálamo, neocorteza, telencéfalo basal, formación reticular, cerebelo y médula espinal (25).

La noradrenalina tiene funciones en el control sueño-vigilia, humor alterado, disminución de la conducta agresiva, aumento de la memoria y el aprendizaje. Una activación moderada del locus coeruleus se relaciona con un buen procesamiento de la información, mientras que una activación excesiva dar lugar a un empobrecimiento de la atención sostenida (18).

En la enfermedad de Alzheimer, el Parkinson, la esquizofrenia, los síndromes maniformes y la depresión se han evidenciado alteraciones tanto en las sinapsis como en las tasas de disparo de las células del locus coeruleus. Además, se sabe que el estrés agudo incrementa la tasa de disparo de neuronas noradrenérgicas, disminuye la concentración de noradrenalina en el cerebro y la incrementa en el espacio extracelular. La noradrenalina también participa en la modulación del dolor y la analgesia, debido a las proyecciones noradrenérgicas que llegan a la médula espinal y a los receptores $\alpha-2$ (10). 


\section{Dopamina}

En el área tegmental ventral y la sustancia nigra del mesencéfalo, esta catecolamina se sintetiza a partir de la tirosina. Ésta es captada por los terminales dopaminérgicos y luego es metabolizada por la enzima tirosina-hidroxilasa y convertida en L-dopa. Finalmente, la L-dopa es descarbolixada y la dopamina resultante es almacenada en las vesículas presinápticas. Un exceso en el almacenamiento de dopamina puede inhibir la tirosina-hidroxilasa y un exceso en su liberación estimula la acción de la misma. Las neuronas dopaminérgicas tienen la particularidad de que pueden liberar dopamina en terminales presinápticos, así como también en los cuerpos celulares y las dendritas.

La tabla 4 describe someramente las 4 vías dopaminérgicas de interés psicofarmacológico ( 1 , $10,18,26)$.

\begin{tabular}{|c|c|c|}
\hline \multicolumn{3}{|c|}{ TABLA 4. VÍAS DOPAMINÉRGICAS } \\
\hline Nombre & Distribución & Fisiología \\
\hline Vía nigroestriatal & $\begin{array}{l}\text { Directa: Incluye estructuras del } \\
\text { estriado medial, el pálido y la } \\
\text { sustancia nigra (pars compacta). } \\
\text { Indirecta: incluye neuronas del } \\
\text { putamen, el pálido, el núcleo } \\
\text { subtalámico y la sustancia nigra } \\
\text { (pars reticulata). }\end{array}$ & $\begin{array}{l}\text { Estimulación del movimiento } \\
\text { intencional. }\end{array}$ \\
\hline Vía mesolímbica & $\begin{array}{l}\text { Desde el área tegmental ventral } \\
\text { al núcleo accumbens, tubérculo } \\
\text { olfatorio, estría terminalis, sep- } \\
\text { tum lateral y regiones de la corte- } \\
\text { za cerebral frontal, entorrinal y } \\
\text { cíngulo. }\end{array}$ & $\begin{array}{l}\text { Motivación, emociones, placer, } \\
\text { recompensa. }\end{array}$ \\
\hline Vía mesocortical & $\begin{array}{l}\text { Desde el área tegmental ventral a } \\
\text { la corteza prefrontal dorsolateral } \\
\text { y ventromedial. }\end{array}$ & $\begin{array}{l}\text { Cognición y función ejecutiva } \\
\text { (corteza prefrontal dorsolateral), } \\
\text { emociones y afectividad (corteza } \\
\text { prefrontal ventromedial). }\end{array}$ \\
\hline Vía tuberoinfundibular & $\begin{array}{l}\text { Desde el núcleo arqueado del } \\
\text { hipotálamo a la cara externa de la } \\
\text { eminencia media de la hipófisis. }\end{array}$ & $\begin{array}{l}\text { Inhibición tónica de la liberación } \\
\text { de prolactina. }\end{array}$ \\
\hline
\end{tabular}

Se recalca que existe una quinta vía dopaminérgica, la denominada vía talámica, más la misma carece de importancia psicofarmacológica y su función no se conoce bien en la actualidad. La transmisión dopaminérgica se encuentra alterada por defecto en la senectud, la enfermedad de Alzheimer y el Parkinson; mientras, se encuentra alterada por aumento en la enfermedad de Huntington y la esquizofrenia $(1,26)$. 


\section{Acetilcolina}

Se sintetiza a partir de la colina y la acetil coenzima A (productos biológicos derivados del metabolismo de la glucosa) a través de la enzima colina acetiltransferasa. Las vías colinérgicas se originan a nivel de la formación reticular del tallo cerebral y se proyectan al hipotálamo, tálamo, vías ópticas, ganglios basales, hipocampo y sistema reticular.

La acetilcolina participa en la regulación de diversas funciones como fenómenos de activación cortical, el paso de sueño a vigilia, procesos de memoria y asociación y control de la unión neuromuscular (27).

La transmisión colinérgica se encuentra disminuida en la senectud, en la enfermedad de Alzheimer, enfermedad de Huntington y esquizofrenia y aumentada en la depresión y el alcoholismo (10).

\section{Glutamato}

Se lo llama también el "interruptor general" del cerebro: capaz de excitar y encender, virtualmente, a todas las neuronas del sistema nerviosa central (18). El glutamato se sintetiza a partir del $\alpha$-Ketoglutarato y la glutamina, por acción de la enzima glutaminasa. Se almacena en vesículas presinápticas y es liberado por despolarización neuronal y, además, por retroalimentación positiva (esto es, una molécula de glutamato liberada se une con un receptor presináptico e induce la liberación de otras moléculas de glutamato). El glutamato es el principal neurotransmisor en la cóclea, retina, bulbo olfatorio y células piramidales de la corteza cerebral. Participa en vías tálamocorticales y corticoestriales y en vías internas del hipocampo.

El glutamato está implicado en diversos procesos neurofisiológicos. Participa en funciones mnésicas, en el aprendizaje y la plasticidad neuronal. Asimismo, está involucrado en la migración neuronal, la sinaptogénesis, representación espacial y organización neuronal de las capas de la corteza en edades tempranas del desarrollo. Es de destacar que el glutamato puede tener efectos neuroprotectores, más una activación excesiva puede producir todo lo contrario, es decir, efectos neurotóxicos $(10,18)$.

Como se mencionó previamente, la sobreexcitación del glutamato produce entrada masiva de iones $\mathrm{Ca}^{+2}$, pudiendo generar excitotoxicidad, con lesión y muerte neuronal, como ocurre en la esclerosis lateral amiotrófica, esclerosis múltiple, enfermedad de Parkinson, enfermedad de Huntington o enfermedad de Alzheimer. Asimismo, en los últimos años el glutamato ha alcanzado un importante papel, al menos a nivel teórico, en la fisiopatología de la esquizofrenia. Además, es actualmente uno de los objetivos en la creación de nuevos agentes psicotrópicos para el tratamiento de la misma (18).

\section{GABA}

El GABA es el neurotransmisor de tipo inhibidor más abundante en el sistema nervioso central, sugiriéndose que el $30 \%$ o $40 \%$ de las neuronas del cerebro utilizan GABA como neuro- 
transmisor. Su existencia en el tejido nervioso garantiza el equilibrio entre excitación e inhibición neuronal, un requisito fundamental en la función sensitiva, cognitiva y motora (28).

Es un ácido orgánico sintetizado a partir del ácido glutámico por acción de la glutamato descarboxilasa y la piridoxina (vitamina B6). El GABA se encuentra en el citoplasma neuronal de células, sobre todo, de la sustancia nigra, núcleo caudado, globo pálido, putamen y corteza cerebral.

El GABA tiene múltiples funciones, a saber: 1. Induce una acción relajante sobre fibras musculares estriadas; 2 . Inhibe la sobreexcitación nerviosa de neuronas piramidales de la corteza, las alteraciones de la conducta y la actividad epileptógena; 3 . Tiene un valor importante como sedante, relajante, anticonvulsivante y ansiolítico; 4. Controla los movimientos extrapiramidales, a través de las vías gabaérgicas que van del estriado a la sustancia nigra; y, 5. Impide la aparición de movimientos coreiformes, a través de las vías que van del estriado al globo pálido y que inhiben el núcleo subtalámico (28).

Por otra parte, la disfunción de la transmisión gabaérgica está presente en: 1. Enfermedad de Huntington; 2. Epilepsia; 3. Discinesia tardía; 4. Enfermedad de Parkinson; 5. Trastornos del sueño; 6. Esquizofrenia (donde se ha encontrado una disminución en el número y anormalidades en la distribución de neuronas gabaérgicas de la corteza, a nivel de la lámina cortical supragranular) (10).

Finalmente, luego de conocer (al menos en resumen) las características de los principales neurotransmisores, es importante recalcar que el objetivo final común de la psicofarmacología es influir en la neurotransmisión anormal en pacientes con trastornos psiquiátricos y esto depende, finalmente, de la utilización de una base racional (a la luz de la evidencia) de psicofármacos, en solitario o combinados.

Esta sección no puede dejar pasar la oportunidad de describir a los neuropéptidos. Actualmente se conocen alrededor de 50 tipos diferentes. Su tamaño molecular es variable y están formados por cadenas de entre 3 y 40 aminoácidos. Las funciones de los neuropéptidos son las siguientes: 1 . Regulación de ingesta de comida y bebida; 2 . Comportamiento sexual; 3. Procesos de aprendizaje y memoria; 4 . Respuestas del organismo a situaciones estresantes; 5. Control del dolor (a través de los opioides y la sustancia P); y, 6. Modulación e influencia de la función hormonal del sistema neuroendocrino (10).

\section{Fenómenos presinápticos: de la transmisión eléctrica a la química}

Los fenómenos presinápticos $(22,29,30)$ que se suceden en un proceso de neurotransmisión química incluyen la síntesis del neurotransmisor, su almacenamiento, su liberación, la estimulación de los receptores presinápticos y, finalmente, la finalización de la acción del neurotransmisor (tabla 5). 
TABLA 5. FENÓMENOS PRESINÁPTICOS

\begin{tabular}{|c|c|}
\hline $\begin{array}{c}\text { Síntesis de los } \\
\text { neurotransmisores }\end{array}$ & $\begin{array}{l}\text { Los neurotransmisores de molécula pequeña (noradrenalina, dopamina, sero- } \\
\text { tonina, histamina, acetilcolina, GABA, glicina, glutamato, etcétera) son sinteti- } \\
\text { zados por vías metabólicas cortas, tanto en el cuerpo de la neurona como en } \\
\text { sus terminales axónicos. Por su parte, los neurotransmisores de molécula gran- } \\
\text { de (neuropéptidos: opioides endógenos, vasopresina, angiotensina, neurotensi- } \\
\text { na, sustancia P, neuropéptido } \mathrm{Y} \text {, entre otros) requieren de vías metabólicas más } \\
\text { complejas, que sólo se producen en el soma neuronal. }\end{array}$ \\
\hline $\begin{array}{c}\text { Almacenamiento } \\
\text { de neurotransmisores }\end{array}$ & $\begin{array}{l}\text { Los neurotransmisores de molécula pequeña se almacenan en vesículas, que } \\
\text { evitan su destrucción por parte de las enzimas citoplasmáticas. Los neurotrans- } \\
\text { misores están ionizados, por lo que no pueden abandonar la vesícula. Un siste- } \\
\text { ma de transporte activo recupera, hacia el interior de las vesículas, a los neuro- } \\
\text { transmisores luego de su liberación. Los neurotransmisores de molécula grande } \\
\text { carecen de enzimas que controlen su concentración intracelular y, cuando son } \\
\text { liberados, su recuperación es más lenta. }\end{array}$ \\
\hline $\begin{array}{c}\text { Liberación } \\
\text { del neurotransmisor }\end{array}$ & $\begin{array}{l}\text { El proceso de liberación de los neurotransmisores ocurre como consecuencia de } \\
\text { la llegada de un impulso nervioso al terminal presináptico, que determina la } \\
\text { apertura masiva de canales de } \mathrm{Ca}^{+2} \text { dependientes de voltaje. } \mathrm{El} \mathrm{Ca}^{+2} \text { que ingresa } \\
\text { a la célula provoca la fusión de las vesículas de almacenamiento con la mem- } \\
\text { brana del terminal presináptico y, consecuentemente, la liberación de neuro- } \\
\text { transmisores a la hendidura sináptica. }\end{array}$ \\
\hline $\begin{array}{l}\text { Estimulación } \\
\text { de receptores } \\
\text { presinápticos }\end{array}$ & $\begin{array}{l}\text { En la membrana presináptica existen dos tipos de receptores: los autorrecepto- } \\
\text { res y los heterorreceptores. Los autorreceptores son activados por el neuro- } \\
\text { transmisor liberado, a fin de informar a la neurona sobre la cantidad de neuro- } \\
\text { transmisor presente en la hendidura sináptica, de manera a autorregular la } \\
\text { liberación del neurotransmisor. Los heterorreceptores se activan por otros neu- } \\
\text { rotransmisores, liberados por otras terminales, como los } \alpha 2 \text {-adrenérgicos pre- } \\
\text { sentes en neuronas serotoninérgicas (cuya estimulación disminuye los niveles } \\
\text { de serotonina liberados). }\end{array}$ \\
\hline $\begin{array}{c}\text { Finalización } \\
\text { de la acción } \\
\text { del neurotransmisor }\end{array}$ & $\begin{array}{l}\text { Una vez que el neurotransmisor ha actuado sobre el receptor postsináptico y } \\
\text { producido su efecto (lo que se describirá más adelante), se hace necesario inte- } \\
\text { rrumpir el mensaje sináptico, a fin de que puedan producirse y transmitirse } \\
\text { nuevas señales en la sinapsis. Para que esto ocurra, el neurotransmisor debe } \\
\text { desaparecer de la hendidura sináptica, ya sea por difusión, por recaptación en } \\
\text { el terminal presináptico, o por metabolización enzimática. }\end{array}$ \\
\hline
\end{tabular}

\section{Fenómenos postsinápticos: transmisión de la información interneuronal}

Los receptores postsinápticos son los responsables de captar la información proporcionada por la neurona presináptica mediante los neurotransmisores liberados. Así, y como se mencionó anteriormente en este artículo, los neurotransmisores provocan, en el terminal postsináptico de la célula con la que están en contacto, cambios electrofisiológicos que se traducen en potenciales postsinápticos excitadores o inhibidores $(22,23)$. Además, en otras ocasiones, el neurotransmisor actúa modulando la acción de otros transmisores, de forma que por sí solo, tiene poco efecto sobre la neurona postsináptica, pero potencia o inhibe la acción de otros transmisores sobre ésta. Este fenómeno recibe el nombre de modulación alostérica. 


\section{Generalidades sobre receptores}

Los receptores son estructuras tridimensionales, de naturaleza proteica, que tienen especificidad estereoquímica para identificar una sustancia, hormona o neurotransmisor.

Los receptores pueden clasificarse, según su localización, en presinápticos y postsinápticos. Los presinápticos pueden ser auto o heterorreceptores y suelen regular la liberación de un neurotransmisor (véase la sección "Estimulación de receptores presinápticos" de la tabla 5 de este artículo). Por su parte, los postsinápticos generan una respuesta en otra neurona. Desde el punto de vista funcional, los receptores pueden ser ionotrópicos o metabotrópicos.

Los receptores ionotrópicos o canales iónicos regulados por ligando determinan la apertura o cierre de canales y producen despolarizaciones (génesis de potenciales de respuesta excitatorios) o hiperpolarizaciones (génesis de potenciales de respuesta inhibitorios). Son de respuesta rápida (1 milisegundo) y están regulados por neurotransmisores. Por otra parte, existen otros canales iónicos sensibles a voltaje, que se abren o cierran según la carga eléctrica a lo largo de la membrana neuronal en la que residen $(18,31)$.

Los receptores metabotrópicos son moléculas independientes acopladas a proteínas $\mathrm{G}$. Son de respuesta lenta (segundos y minutos) y están unidos a distintas unidades efectoras que pueden ser canales iónicos o enzimas que pueden generar segundos mensajeros y complejas cascadas bioquímicas (18).

\section{Interacciones fármaco-receptor}

Los psicofármacos tienen muchas formas de interactuar con los receptores metabotrópicos acoplados a proteínas $\mathrm{G}$ y con los receptores iónicos regulados por ligando. Estas interacciones tienen lugar a lo largo del llamado "espectro agonista".

Los neurotransmisores que existen naturalmente estimulan a los receptores y son, por tanto, agonistas. Algunos fármacos también estimulan a los receptores y son por ellos agonistas también (activando la síntesis del segundo mensajero al máximo posible en el caso de receptores acoplados a proteínas $\mathrm{G}$ o abriendo el canal iónico en las frecuencias y cantidades máximas permitidas en el caso de canales iónicos regulados por ligando). Los fármacos también pueden estimular los receptores en un menor grado que el neurotransmisor natural: los llamados agonistas parciales. Los antagonistas bloquean la acción del neurotransmisor agonista natural (alterando la configuración del receptor acoplado a proteína $\mathrm{G}$ a fin de que éste solo mantenga una actividad basal, constitutiva; o manteniendo el estado de reposo del canal iónico, con aperturas infrecuentes). Finalmente, los agonistas inversos están más allá que los antagonistas, puesto que incluso la actividad constitutiva del receptor es bloqueada, produciendo un cambio de configuración de los receptores acoplados a proteínas $G$, que los vuelve inactivos. En el caso de un canal iónico regulado por ligando, un agonista inverso se une al sitio de unión, cerrando el canal iónico e inactivándolo $(10,18,30,31)$. 


\section{Los receptores como estructuras dinámicas}

Los receptores son estructuras dinámicas, cuya densidad y sensibilidad varían en función de los cambios de su entorno. Así, la actividad receptorial puede reducirse, bien por una disminución en el número de receptores disponibles, debido a limitaciones en su síntesis y transporte axonal (down-regulation) o bien por una pérdida de sensibilidad (desensibilización), que puede ser provocada por factores tales como la fosforilación del receptor, internalización o reducción de los mensajeros intracelulares acoplados. Estos fenómenos tienen lugar ante una estimulación receptorial prolongada. Asimismo, puede darse la situación contraria, en casos de bloqueo receptorial prolongado. En estas condiciones, puede aumentar la síntesis de receptores y, por lo tanto, su número (up-regulation) o su sensibilidad (hipersensibilización).

Antes de finalizar esta sección de generalidades sobre receptores, se hace necesario describir el concepto de modulación alostérica. Los canales iónicos regulados por ligando interaccionan con más neurotransmisores de los que se unen a ellos $(18,32)$. Es decir, existen otras moléculas que no son neurotransmisores pero que pueden unirse al complejo receptor/canal iónico en sitios distintos de donde se unen los neurotransmisores (sitios alostéricos). Estas moléculas son moduladoras y funcionan sólo en presencia de un neurotransmisor, es decir por sí solos tienen muy poca o ninguna actividad. La modulación alostérica puede ser positiva o negativa.

Cuando un neurotransmisor se une al receptor activando un canal de iones, el canal se abre más frecuentemente. Sin embargo, cuando tanto el neurotransmisor como un modulador alostérico positivo se unen al receptor, el canal se abre con mucha frecuencia, permitiendo la entrada de más iones en la célula. Las benzodiazepinas son ejemplos de moduladores alostéricos positivos, puesto que potencian la acción del GABA en receptores iónicos de cloro tipo GABA-A (el GABA incrementa el flujo iónico de cloro mediante la apertura del canal iónico y las benzodiazepinas que se unen al sitio alostérico amplifican el efecto del GABA en términos de flujo iónico de cloro al abrirse el canal a un mayor grado y más frecuentemente).

Por su parte, en la modulación alostérica negativa tanto el neurotransmisor como un modulador alostérico negativo se unen al receptor, lo que hace que el canal se abra con mucha menos frecuencia, con la consiguiente entrada de menos iones en la célula (18).

\section{Transducción de la señal}

La transducción de la señal es la puesta en marcha de las respuestas celulares tras el estímulo de los receptores. El mecanismo implicado es complejo y escapa a las intenciones de este artículo. No obstante, conviene puntualizar que el proceso de transducción se lleva a cabo gracias a una cascada de procesos bioquímicos (modificación del flujo de iones y de los potenciales bioeléctricos), cambios en la actividad enzimática y cabios en la expresión genética neuronal, que llegan a modificar la síntesis y estructura de diversas proteínas. En caso que el lector desee profundizar más este tema, se recomienda la lectura del libro "Psicofarmacología Esencial" del profesor Stephen Stahl (Editorial Aula Médica, 2014). 


\section{DIANAS DE LA ACCIÓN PSICOFARMACOLÓGICA}

La mayoría de las sustancias psicoactivas (psicofármacos y drogas de abuso), ejercen sus efectos sobre el sistema nervioso central al afectar los mecanismos de neurotransmisión química y una serie de objetivos moleculares.

\section{Alteración de mecanismos de la neurotransmisión}

La neurotransmisión química puede alterarse en alguno de estos niveles: 1 . Síntesis y almacenamiento de neurotransmisores; 2 . Proceso de liberación del neurotransmisor; y, 3. En lo referente a la inactivación del neurotransmisor (10).

Alteración a nivel de la síntesis y almacenamiento de neurotransmisores

Se pueden dar tres tipos de alteraciones en este sentido:

- Inhibiendo la síntesis de neurotransmisores: Por ejemplo, la $\alpha$-metil-p-tirosina (AMPT) es una molécula inhibidora de la enzima tirosina-hidroxilasa, con la cual se impide el paso de tirosina a L-dopa y, consecuentemente, se disminuye la síntesis de dopamina y noradrenalina.

- Proporcionando a la neurona mayor cantidad de sustancia precursora; por ejemplo, algunos fármacos que se utilizan en la enfermedad de Parkinson proveen de mayores cantidades de L-dopa, con la cual las neuronas pueden sintetizar mayores cantidades de dopamina.

- Inhibiendo la recaptación de neurotransmisores en las vesículas de almacenamiento de los terminales presinápticos, con lo que los mismos se encuentran desprotegidos y expuestos a la degradación enzimática (por ejemplo, a las monoamino-oxidasas). Un ejemplo es la reserpina, que depleciona las reservas de serotonina y noradrenalina en el cerebro, médula suprarrenal, y otros tejidos, y reduce la recaptación de catecolaminas por los terminales nerviosos adrenérgicos.

Alteración a nivel del proceso de liberación de neurotransmisores

Dos son las alteraciones que pueden afectar este proceso:

- Disminuyendo la entrada de iones $\mathrm{Ca}^{+} 2$ al terminal presináptico mediante, por ejemplo, el aumento de las concentraciones de $\mathrm{Mg}^{+2}$, que es un ion que compite con el $\mathrm{Ca}^{+2}$ para entrar a la célula.

- Agotando las fuentes de un neurotransmisor. Por ejemplo, el veneno de arañas de género Latrodectus (viuda negra) puede provocar una liberación masiva de acetilcolina, provocando convulsiones, parálisis muscular y afectación de funciones fisiológicas controladas por el sistema nervioso autónomo que pueden llevar a la muerte 
Alteración a nivel del proceso de inactivación de neurotransmisores

Dos son también las alteraciones que pueden afectar este proceso:

- Algunas sustancias inhiben las enzimas que afectan la degradación de los neurotransmisores, aumentado por ende su concentración en la hendidura sináptica y potenciando de esa forma su efecto. A modo de ejemplo, existen sustancias que inhiben la acetilcolinesterasa, enzima encargada de degradar la acetilcolina. Estas sustancias pueden ser:

1. Inhibidores irreversibles: Como los fosfatos orgánicos (ésteres del ácido fosfórico), utilizados en algunos insecticidas y plaguicidas, y muy neurotóxicos.

2. Inhibidores reversibles: Como el donepezilo, fármaco diseñado para el tratamiento de la enfermedad de Alzheimer, que inhibe de manera reversible a la acetilcolinesterasa y, secundariamente, a la butirilcolinesterasa, aumentando de esa manera la concentración de la acetilcolina en la hendidura sináptica $(33,34)$.

- Otro mecanismo es el producido por sustancias que impiden que los neurotransmisores (dopamina, serotonina y noradrenalina) sean recaptados adecuadamente por el terminal presináptico, aumentando así también la concentración de los mismos en la hendidura sináptica. Esta es la base de la acción de muchos fármacos antidepresivos, como los inhibidores selectivos de la recaptación de serotonina (citalopram, escitalopram, fluoxetina, fluvoxamina, paroxetina, sertralina), los inhibidores de la recaptación/antagonistas de serotonina (trazodona), inhibidores de la recaptación de dopamina-noradrenalina (bupropión), inhibidores de la recaptación de noradrenalina (atomoxetina, reboxetina), inhibidores de la recaptación de serotonina-noradrenalina (duloxetina, venlafaxina) y de los inhibidores duales de la recaptación de serotonina (vilazodona) (34).

\section{Objetivos moleculares de los psicofármacos}

Los psicofármacos poseen mecanismos de acción muy diversos, pero todos tienen sus objetivos en zonas moleculares específicas que producen cambios en la neurotransmisión. Si bien algunos de los conceptos que se detallan en esta sección ya han sido discutidos previamente (véanse los apartados "Interacciones fármaco-receptor", "Modulación alostérica" y "Alteración de mecanismos de la neurotransmisión" de este artículo), se considera necesario puntualizar algunos elementos.

Existen solo unas pocas zonas de acción principales para la amplia variedad de fármacos psicotrópicos utilizados en la práctica clínica diaria (18), a saber: 1 . Transportadores de neurotransmisores; 2. Receptores acoplados a proteínas G; 3. Enzimas; 4. Canales iónicos regulados por ligando; $y, 5$. Canales iónicos sensibles a voltaje.

- Alrededor del 30\% de los psicofármacos tienen como objetivo uno de los transportadores de neurotransmisores (tanto de recaptación presináptica como de almacenamiento vesicular) para un neurotransmisor. 
Ambos tipos de transporte de neurotransmisor (tanto la recaptación presináptica como el almacenamiento vesicular) utilizan un trasportador molecular proteico con doce regiones transmembrana.

A nivel de la membrana presináptica de las neuronas monoaminérgicas se encuentran el transportador de dopamina (DAT), el transportador de serotonina (SERT, también expresado en las plaquetas) o el transportador de noradrenalina (NET), según sea el tipo de neurona monoaminérgica en cuestión. Estos transportadores proteicos utilizan gradientes iónicos $\left(\mathrm{Na}^{+}, \mathrm{Cl}^{-}\right)$como fuente de energía, para movilizar monoaminas. La función principal de estos transportadores es finalizar la transmisión monoaminérgica al recaptar a las monoaminas hacia el interior de la terminal presináptica, lejos de la hendidura sináptica. Aunque los transportadores presinápticos monoaminérgicos (DAT, SERT, NET) son únicos en sus secuencias de aminoácidos y afinidades de unión para las monoaminas, cada transportador monoaminérgico presináptico tiene una considerable afinidad por otras aminas distintas a aquella que corresponde a su propia neurona (35). DAT, SERT y NET son objetivos claves para la mayoría de los antidepresivos conocidos (inhibiendo su función y aumentando, consecuentemente, la monoamina que transportan en la hendidura sináptica).

Debido a la expresión exclusiva de cada transportador en las neuronas correspondientes, estos transportadores se utilizan a menudo como marcadores de neuronas específicas. El DAT se expresa en las neuronas dopaminérgicas que se proyectan principalmente del área tegmental ventral y la sustancia nigra a la corteza prefrontal, al núcleo accumbens y al cuerpo estriado; el SERT juega su papel en la protuberancia y tronco cerebral superior; $y$, por su parte, el NET se localiza en neuronas del locus coeruleus y del grupo tegmental lateral, que se proyectan hacia muchas otras regiones del cerebro.

Por su parte, en la membrana de las vesículas sinápticas intracelulares de los terminales presinápticos se encuentran los transportadores vesiculares de monoaminas 1 y 2 (VMAT1 y VMAT2), que utilizan un gradiente de protones $\left(\mathrm{H}^{+}\right)$como fuente de energía, para almacenar monoaminas citosólicas en las vesículas, que luego podrán ser liberadas en la hendidura sináptica por exocitosis. EI VMAT2 es el principal transportador vesicular en las neuronas monoaminérgicas (36) y es un objetivo farmacológico del estimulante anfetamina.

Las neuronas monoaminérgicas se relacionan entre sí y con muchos otros tipos de neuronas de varias regiones del cerebro, incluyendo la corteza, el hipocampo, la amígdala y el hipotálamo. La amplia distribución de los transportadores de monoaminas determina sus roles centrales en la neurotransmisión y los hace objetivos ideales de la medicación psicotrópica en un amplio espectro de trastornos, que incluyen al trastorno por hiperactividad con déficit de atención, la depresión, los trastornos de ansiedad, las adicciones, la narcolepsia, los trastornos de la conducta alimentaria, la esquizofrenia, el trastorno bipolar y la enfermedad de Parkinson (1). Por otro lado, estos transportadores también tienen papeles centrales como objetivos funcionales de las drogas de abuso tales como el alcohol, la cocaína, la metanfetamina y el éxtasis. 
- Otro 30\%, actúa sobre receptores metabotrópicos acoplados a proteínas G.

Los receptores metabotrópicos acoplados a proteínas $\mathrm{G}$ o simplemente receptores acoplados a proteínas $\mathrm{G}$, conocidos también como receptores transmembrana de siete dominios, comprenden una gran familia de proteínas de receptores transmembrana que perciben moléculas afuera de la célula y activan las vías de transducción de señales (a través de la vía de señal del cAMP o la vía de señal del fosfatidilinositol) para producir, finalmente, las respuestas celulares. Los receptores acoplados a proteínas $\mathrm{G}$ están involucrados en muchas enfermedades, y en psiquiatría son el blanco de aproximadamente un tercio de los psicofármacos conocidos (37).

Las acciones de los fármacos en estos receptores ocurren en un espectro que abarca desde las acciones del agonista total, a las acciones del agonista parcial, pasado por las del antagonista e incluso por las del agonista inverso (véase el detalle del "espectro agonista" en el apartado "Interacciones fármaco-receptor" del presente artículo).

Los neurotransmisores naturales son agonistas totales, así como algunos fármacos usados en la práctica clínica. No obstante, la mayoría de los fármacos que actúan sobre los receptores acoplados a proteínas $\mathrm{G}$ funcionan como antagonistas. Unos pocos actúan como agonistas parciales y algunos como agonistas inversos. La siguiente lista ilustrativa presenta algunos ejemplos $(18,19,24-28,38)$ :

1. Los antipsicóticos típicos actúan como antagonistas de los receptores D2 de la dopamina, con efecto antipsicótico y antimaniaco;

2. Los antipsicóticos atípicos actúan como antagonistas de los receptores D2 de la dopamina (produciendo un efecto antipsicótico y antimaniaco) y, simultáneamente, como antagonistas de los receptores $5 \mathrm{HT} 2$ de la serotonina (lo que permite que mejoren o no empeoren tanto los efectos secundarios del bloqueo D2 producido por la terapia antipsicótica);

3. El $Y$-hidroxibutirato es agonista total de los receptores GABA-B del GABA;

4. Muchos antipsicóticos y antidepresivos poseen actividad antagonista del receptor $\alpha-1$ de la noradrenalina, generando efectos adversos de hipotensión ortostática y posible sedación;

5. La agomelatina es agonista total de los receptores $\mathrm{MT}_{1}$ y $\mathrm{MT}_{2}$ de la melatonina, con lo que mejora el insomnio;

6. Muchos antipsicóticos y antidepresivos (y algunos ansiolíticos) son antagonistas del receptor $\mathrm{H} 1$ de la histamina, logrando efectos terapéuticos para la ansiedad y el insomnio y efectos adversos de sedación y ganancia de peso;

7. Muchos antipsicóticos atípicos y antidepresivos son antagonistas del receptor muscarínico M1 de la acetilcolina y generan, por ende, efectos secundarios de alteración de la memoria, sedación, boca seca, visión borrosa, estreñimiento y retención urinaria; y, 
8. Algunos antipsicóticos atípicos son antagonistas de los receptores muscarínicos M3/M5 de la acetilcolina, contribuyendo a producir alteraciones metabólicas, dislipidemia y diabetes.

- Las enzimas son el objetivo del $10 \%$ de los psicotrópicos.

La actividad enzimática es la conversión de una molécula en otra, o más específicamente, de un sustrato en un producto. Los sustratos para cada enzima son únicos y selectivos, como son los productos. Un sustrato se une a su enzima en un sitio activo y, finalmente, es transformado en un producto que abandona la enzima. En presencia de un inhibidor, la enzima no puede unirse a su sustrato.

Tal como se mencionó en el apartado "Alteración a nivel del proceso de inactivación de neurotransmisores", existen dos tipos de inhibición enzimática: irreversible y reversible $(18,33$, 34):

1. En la inhibición irreversible, un sustrato no puede eliminar a la molécula inhibidora que se ha unido a la enzima. La actividad enzimática no puede ser restaurada a menos que otra molécula de la enzima sea sintetizada por la célula. Ejemplo de inhibición enzimática irreversible es la utilizada por los antidepresivos IMAO (inhibidores de la monoamino-oxidasa) clásicos; y,

2. Por el contrario, en la inhibición reversible el sustrato es capaz de eliminar a la molécula inhibidora de la enzima, con lo que la actividad enzimática queda restaurada. Ejemplo de inhibición enzimática reversible es la ejercida por el donepezilo con la actividad de la acetilcolinesterasa (1).

Es de destacar a las enzimas del sistema de metabolización de fármacos del citocromo P450 (CYP) hepático. Específicamente, es importante puntualizar que el consumo de tabaco (muy frecuente en pacientes con esquizofrenia) induce la actividad de la enzima CYP 1A2, reduciendo la concentración de fármacos metabolizados por la misma (olanzapina, clozapina y otros). Los fumadores, por tanto, pueden necesitar dosis más altas de estos fármacos que los no fumadores (39).

- Los canales iónicos regulados por ligando representan el objetivo de un $20 \%$ de los psicofármacos.

También llamados ionotrópicos. Son un grupo de canales iónicos proteicos transmembranosos que se abren para permitir el flujo iónico de $\mathrm{Na}^{+}, \mathrm{K}^{+}, \mathrm{Ca}^{+2} \mathrm{o} \mathrm{Cl}^{-}$a través de la membrana celular en respuesta a la unión de un mensajero químico ("ligando"), como lo es un neurotransmisor (40).

Las acciones de los fármacos en estos receptores ocurren, también, en un espectro que abarca desde las acciones del agonista total, a las acciones del agonista parcial, pasado por las del antagonista e incluso por las del agonista inverso (véase el detalle del "espectro agonista" en el apartado "Interacciones fármaco-receptor" del presente artículo). 
La siguiente lista ilustrativa presenta algunos ejemplos de cómo los psicofármacos actúan a nivel de los canales iónicos regulados por ligando (18, 19, 24-28, 38):

1. La vareniclina es un agonista parcial del receptor nicotínico $\alpha_{4} \beta_{2}$ de la acetilcolina, con efecto probado en el abandono del tabaco;

2. Las benzodiazepinas son agonistas completos de los receptores benzodiazepínicos GABA-A del GABA y poseen efecto ansiolítico;

3. Los fármacos $Z$ (zolpidem, eszopiclona) son también agonistas completos del receptor GABA-A del GABA. Su efecto es la mejoría del insomnio;

4. La memantina es un fármaco antagonista de los receptores NMDA (sitios de modulación alostérica negativa/sitios de $\mathrm{Mg}+2$ ) del glutamato. El antagonismo produce enlentecimiento en la progresión de la enfermedad de Alzheimer; $y$,

5. El antidepresivo mirtazapina es un antagonista de los receptores 5HT3 de la serotonina. Su efecto terapéutico es desconocido, aunque está probado que reduce las náuseas.

- Finalmente, el $10 \%$ de los psicofármacos tiene como objetivo a los canales iónicos sensibles a voltaje.

Estos canales iónicos se abren y cierran según los cambios de voltaje a lo largo de la membrana neuronal en la que residen. De interés en el campo de la psicofarmacología son el canal de sodio sensible a voltaje y el canal de calcio sensible a voltaje $(18,19,38)$ :

1. El valproato ejerce efectos antimaníacos modificando la sensibilidad de los canales de sodio regulados por voltaje, ya sea uniéndose directamente a subunidades del canal o inhibiendo enzimas que regulan la sensibilidad de estos canales iónicos;

2. La carbamazepina actúa uniéndose a la subunidad $\alpha$ de los canales de sodio sensibles a voltaje, pudiendo tener además acciones sobre canales iónicos de calcio y de potasio. Además, la carbamazepina potencia la acción inhibitoria del GABA, mediante la interferencia en los canales iónicos sensibles a voltaje;

3. La lamotrigina reduce la liberación del neurotransmisor excitador glutamato, a través del bloqueo de canales de sodio sensibles a voltaje;

4. El litio, por ejemplo, actúa sobre las bombas iónicas, dando lugar a efectos adversos hormonales y renales y, probablemente, terapéuticos (22); y,

5. Tanto la gabapentina como la pregabalina son utilizadas para el tratamiento de diversos cuadros dolorosos (desde el dolor neuropático hasta la fibromialgia) y trastornos de ansiedad. Molecularmente, ambas son ligandos $\alpha 2 \delta$ puesto que se unen selectivamente y con alta afinidad a la subunidad $\alpha 2 \delta$ de canales de calcio sensibles a voltaje, lo que termina impidiendo la liberación de neurotransmisores como el glutamato 
en vías relacionadas con la ansiedad y el dolor, previniendo también la aparición de convulsiones.

\section{ASPECTOS GENERALES DE FARMACOCINÉTICA Y FARMACODINÁMICA}

Los continuos progresos de la psicofarmacología están permitiendo ampliar enormemente la gama de tratamientos psiquiátricos, puesto que se están desarrollando fármacos más eficaces, menos tóxicos, mejor tolerados y con una acción más localizada y específica $(41,42)$. No obstante, a estos avances, la posibilidad de aparición de efectos indeseados o interacciones medicamentosas peligrosas hace que los médicos estén obligados a mantenerse actualizados y a saber cómo actuar a fin de preservar la integridad física y mental del paciente.

Asimismo, la psicofarmacología debe, necesariamente, ser compatibilizada en numerosos casos con prácticas psicoterapéuticas (por ejemplo, la mayoría de los pacientes con diagnóstico de depresión mayor se beneficiará de una terapia combinada con fármacos y psicoterapia) y con otros tratamientos biológicos (la terapia electroconvulsiva, fundamentalmente); otros pacientes, en cambio, sólo necesitarán de psicoterapia. Por todo lo anterior, el médico debe actuar guiado por el principio de humanidad respetando al paciente, a sus derechos humanos, definiendo los objetivos terapéuticos, utilizando solo aquellos tratamientos justificados por la evidencia y estableciendo una buena alianza terapéutica con el paciente.

\section{Consideraciones generales}

El manejo adecuado de los psicofármacos exige el conocimiento de sus características farmacocinéticas y farmacodinámicas. La farmacocinética describe "lo que el cuerpo humano le hace al fármaco", y la farmacodinámica describe "lo que el fármaco le hace al cuerpo" (21). A continuación, se analizarán estos conceptos.

\section{Farmacocinética}

Bajo el concepto general de farmacocinética se engloban todos los procesos biológicos que ocurren en el organismo desde la administración del fármaco hasta que éste se encuentre en su lugar de acción y, posteriormente, sea eliminado (43).

Por tanto, la farmacocinética estudia el curso temporal de las concentraciones de los fármacos en el organismo y construye modelos para interpretar esos datos y para valorar (o predecir) la acción terapéutica o tóxica de un fármaco.

Los componentes de la farmacocinética son los procesos LADME: liberación, absorción, distribución, metabolismo y excreción (44), que serán descriptos a continuación.

\section{- Vías de administración}

La principal vía de administración de los psicofármacos es, sin lugar a dudas, la oral, aunque algunas benzodiazepinas (diazepam, midazolam) pueden administrarse por vía parenteral, así como algunos antipsicóticos, bien mediante formulaciones convencionales (haloperidol, levomepromazina), intramusculares de depósito (decanoato de haloperidol, entre otros), o 
microesferas de polímeros biodegradables (risperidona). Asimismo, se han desarrollado sistemas de liberación modificada para formulaciones por vía oral, ya sea prolongada (quetiapina XR, por ejemplo) o mediante mecanismo osmótico (metilfenidato oros). Con los métodos de liberación retardada, oral y parenteral, se pretende reducir el número de tomas, prolongando las concentraciones y los efectos de los psicofármacos (41). En los últimos años se ha explorado la vía inhalatoria, a través de la formulación de un polvo con loxapina (antipsicótico típico), que representa una alternativa a las inyecciones intramusculares para tratar la agitación aguda en adultos. Las vías de administración de fármacos se discutirán nuevamente más adelante en este artículo.

\section{- Transporte de fármacos a través de las barreras biológicas}

Los fármacos son capaces de atravesar las membranas celulares por diferentes mecanismos, entre los que se destacan la difusión pasiva y el transporte activo. Los mecanismos de transporte activo requieren de la existencia de un transportador de membrana, generalmente saturable, que conduce al fármaco contra un gradiente electroquímico, precisan de energía (ATP) y suelen asociarse al transporte de iones $\left(\mathrm{H}^{+} \circ \mathrm{Na}^{+}\right)$. El transporte activo tiene algún grado de trascendencia en el caso de la barrera hematoencefálica, el aparato gastrointestinal y biliar y los túbulos renales. La L-dopa, por ejemplo, se absorbe de manera activa merced a sus transportadores (41).

No obstante, la mayoría de los fármacos psicotrópicos administrados por vía oral, debido a su alta liposolubilidad y a su pequeño tamaño, atraviesan las membranas biológicas mediante procesos de difusión pasiva, siguiendo gradientes de concentración. La velocidad de este proceso está controlada por la ley de Fick: la velocidad se incrementa cuanto menor sea el tamaño molecular y mayores sean la liposolubilidad del fármaco y el gradiente de concentración.

A su vez, la liposolubilidad guarda relación con el nivel de ionización del fármaco: las formas ionizadas son hidrosolubles, polares e hidrofílicas, por lo que difunden mal a través de las membranas biológicas. La mayoría de los fármacos son ácidos o bases débiles y cuando se hallan en disolución se encuentran parcialmente ionizados, existiendo un equilibrio entre la fracción ionizada y no ionizada. El pH del entorno del fármaco, por lo tanto, influencia su absorción, debido a su capacidad para ionizar sus moléculas (44).

\section{- Liberación}

El proceso de liberación de un fármaco consta de las siguientes etapas: 1. Disgregación: paso de formas sólidas a partículas más pequeñas; 2 . Disolución: paso de formas sólidas a solución (etapa de mayor transcendencia); y, 3. Difusión: paso del fármaco disuelto a través del fluido (19).

\section{- Absorción}

Es el proceso farmacocinético mediante el cual un fármaco, administrado por cualquier vía, llega a la circulación general, para lo cual el fármaco debe liberarse de su forma farmacéuti- 
ca (véase "liberación", más arriba), disolverse en el medio y alcanzar finalmente el torrente circulatorio.

La velocidad de absorción y la propia cantidad del fármaco absorbido dependen de la forma farmacéutica del psicotrópico en cuestión, de la vía de administración utilizada y de factores ajenos al propio fármaco, como la ingestión de alimentos, la existencia de trastornos gastrointestinales (en el caso de la vía oral), trastornos del flujo sanguíneo muscular (en el caso de la vía parenteral) y factores iatrogénicos, si se coadministran, por ejemplo, otros fármacos que modifican la motilidad gastrointestinal (41).

En general, los psicofármacos, prescriptos por vía oral, debido a su alta liposolubilidad son absorbidos por procesos de difusión pasiva, por lo que, en ausencia de patología gastrointestinal o de administración simultánea de antiácidos o de sustancias dotadas de actividad anticolinérgica, la absorción no tendría por qué modificarse significativamente (44).

La vía oral es cómoda, barata y unipersonal, adecuada para el tratamiento crónico (muy frecuente en la práctica psiquiátrica), más requiere voluntad del paciente $y$, a veces, supervisión cercana. Los preparados con cubierta entérica evitan la absorción en el estómago y retrasan el comienzo de la absorción, pero no su velocidad. Tal como se mencionó más arriba, los preparados de liberación modificada enlentecen la absorción y permiten reducir las fluctuaciones de las concentraciones plasmáticas o el número de tomas al día para mejorar el cumplimiento terapéutico (45).

En la vía sublingual, el fármaco es depositado debajo de la lengua y se absorbe por la mucosa sublingual, accediendo por la vena cava a la aurícula derecha. De esta forma, se evita el paso intestinal y hepático, consiguiéndose un efecto más rápido e intenso, útil en situaciones agudas (como el tratamiento de una crisis de pánico con alprazolam sublingual).

La vía intravenosa es de elección en situaciones de crisis. Sus ventajas son la rapidez de la acción y la precisión de las concentraciones plasmáticas que se alcanzan, al no depender de los procesos de absorción ni de los factores que pueden alterarlos. Sus inconvenientes son la dependencia de personal especializado, la posibilidad de reacciones graves (especialmente cuando la administración es muy rápida y se alcanzan altas concentraciones) y el peligro de embolias e infecciones. Estos inconvenientes son los que hacen que los clínicos opten por la vía intramuscular, antes que la endovenosa, en caso de que un fármaco pueda ser administrado por ambas vías (por ejemplo, en el delirium hiperactivo, el antipsicótico haloperidol es indicado a una dosis de 1-2,5 mg por vía intravenosa o intramuscular, cuatro veces/día; normalmente, los clínicos utilizarán la vía intramuscular) (45).

Por su parte, y propiamente dicha, la vía intramuscular se utiliza para conseguir un efecto rápido, ya que la rica vascularización del músculo permite una veloz absorción (en 10 a 30 minutos). No obstante, en algunos casos la absorción intramuscular es lenta o errática (por ejemplo, diazepam) y algunos fármacos como la fenitoína precipitan al pH fisiológico del tejido muscular, por lo que no deben administrarse por esta vía. Asimismo, debe destacarse que la vía intramuscular puede resultar lenta e incompleta cuando hay hipoperfusión tisular (por ejemplo, en la insuficiencia cardíaca) o estasis (por ejemplo, en el embarazo). Una ventaja de la vía intramuscular es su capacidad de asegurar el cumplimiento terapéutico en pa- 
cientes en los que los regímenes de medicación por vía oral no pueden ser cumplidos correctamente. Por ejemplo, tanto el decanoato de haloperidol como la pipotiazina son antipsicóticos de formulación depot que se utilizan en el tratamiento de pacientes con esquizofrenia y baja adherencia al tratamiento por vía oral (47).

Finalmente, a través de la vía inhalatoria, el acceso de los fármacos a la circulación sistémica es rápido, debido a la gran superficie de absorción, que en un adulto de $70 \mathrm{Kg}$ de peso corporal es de alrededor de $200 \mathrm{~m}$. La absorción de los fármacos a través de esta vía de administración está condicionada a las características ventilatorias del paciente, al estado de las mucosas y del tono bronquial y, al tamaño de las partículas atomizadas. La desventaja principal es la aparición de irritación en el epitelio pulmonar y la posibilidad de broncoespasmo con ciertos fármacos.

Un concepto relacionado con el proceso de absorción es la biodisponibilidad. La misma indica la cantidad de fármaco que está disponible para acceder a los tejidos y producir un efecto. La biodisponibilidad se puede cuantificar en magnitud (cantidad de dosis aprovechada) y en velocidad (velocidad de absorción de dicha fracción) (44). La biodisponibilidad es una variable importante, porque la normativa de la Food and Drug Administration (FDA) de los Estados Unidos de América exige que la biodisponibilidad de una formulación genérica no puede diferir de la de la droga original en más del 30\% (21).

\section{- Distribución}

Los fármacos que circulan unidos a las proteínas plasmáticas se denominan fijados a proteínas, y los que circulan sin fijar se denominan libres. Sólo la fracción libre de los fármacos puede es capaz de continuar con los procesos farmacocinéticos y atravesar, por ejemplo, la barrera hematoencefálica. La distribución de un fármaco en el cerebro está controlada por el flujo sanguíneo cerebral, la barrera hematoencefálica y la afinidad del psicotrópico por sus receptores en el cerebro. Las acciones de un fármaco se ven favorecidas, por tanto, por un torrente circulatorio encefálico elevado, una alta liposolubilidad y una alta afinidad receptorial $(21,43,44)$.

Vale la pena acotar que existen zonas del sistema nervioso central no protegidas por la barrera hematoencefálica (eminencia media, área postrema, glándula pineal), por lo que el acceso de los fármacos a ellas es mucho más fácil, destacando en este sentido el centro del vómito (41).

El volumen de distribución valora la capacidad de un fármaco de distribuirse por el organismo. Un fármaco con alto volumen de distribución indica que el mismo se distribuirá bien en los tejidos.

Se estima que un fármaco tiene un volumen de distribución elevado cuando éste es superior al agua corporal total $(0,6 \mathrm{l} / \mathrm{kg})$. Lo anterior es importante por lo siguiente: cuando se administra un fármaco con un amplio volumen de distribución y un gran carácter lipofílico (por ejemplo, las benzodiazepinas), una parte importante del fármaco se encontrará retenida en el tejido graso corporal, siendo la cantidad total de fármaco disponible muy reducida en comparación con la cantidad administrada. Asimismo, la disminución del contenido hídrico 
del cuerpo que experimentan ciertos pacientes (como los adultos mayores) puede decantarse en un incremento de los niveles plasmáticos y tisulares de psicofármacos más hidrófilos, como el litio (41).

- Metabolismo

El metabolismo se produce normalmente en el hígado, a través de cuatro vías principales: oxidación, reducción, hidrólisis y conjugación. El metabolismo generalmente produce sustancias (metabolitos) inactivos que se excretan con facilidad; no obstante, también transforma muchos "profármacos" inactivos en metabolitos activos desde el punto de vista terapéutico.

Dos conceptos importantes dentro del proceso metabólico de un fármaco son la semivida y el efecto de primer paso. La semivida de un fármaco es la cantidad de tiempo que se necesita para, mediante el metabolismo y la excreción, reducir a la mitad una concentración plasmática determinada. Un fármaco administrado uniformemente a intervalos más cortos que su semivida alcanzará el $97 \%$ de su concentración plasmática en equilibrio estacionario después de cinco semividas (21).

El efecto de primer paso se refiere al metabolismo inicial de los fármacos administrados dentro de la circulación portal del hígado. Se describe como la fracción de fármaco absorbido que, sin ser metabolizado, alcanza la circulación sistémica.

La inactivación de la mayoría de los psicotrópicos se realiza a nivel del sistema enzimático del citocromo P450, localizado, fundamentalmente, en el retículo endoplasmático liso de los hepatocitos. Este sistema enzimático está sujeto tanto la inhibición como a la inducción. Los fármacos interactúan de dos maneras con las isoenzimas del citocromo P450: 1 . Como sustratos, para su metabolización; o, 2. Como modificadores de su actividad, dando lugar a una inducción o bien una inhibición enzimática.

El alcohol, el tabaco (véase arriba la sección "Objetivos moleculares de los psicofármacos") y determinados psicofármacos (por ejemplo, barbitúricos y antiepilépticos) inducen la actividad de una isoenzima del citocromo P450 y generan, por tanto, una disminución de un sustrato metabolizado por la misma. Por ejemplo, la cimetidina (antagonista de los receptores H2 de histamina del estómago, comercializada para el tratamiento de la úlcera péptica) induce la actividad de la isoenzima CYP $3 \mathrm{~A} 4$ y, por tanto, disminuye la concentración plasmática de un sustrato metabolizado por ella, como el alprazolam (una benzodiazepina).

Asimismo, algunos fármacos pueden inhibir la actividad de una determinada isoenzima, enlenteciendo el metabolismo de sus sustratos. Por ejemplo, la fluoxetina (antidepresivo inhibidor selectivo de la recaptación de serotonina) es inhibidora del CYP 2D6; al reducirse la actividad enzimática, un sustrato de CYP 2D6, como la amitriptilina (antidepresivo tricíclico), aumentaría su concentración plasmática $(21,41,43,44,46)$. Para mayores detalles acerca de los psicotrópicos que son sustrato de isoenzimas del citocromo P450, y de sus inductores e inhibidores representativos, se recomienda al lector consultar la sección "Farmacocinética e interacciones medicamentosas" del libro "Kaplan \& Sadock. Sinopsis de psiquiatría", de Sadock, Sadock y Ruiz (Editorial Wolters Kluwer, 11a edición, 2015). 


\section{- Excreción}

El riñón es el principal órgano encargado de la excreción de los fármacos. El sistema biliar también contribuye en la eliminación de algunos fármacos y, en mucha menor medida, éstos también pueden eliminarse a través del sistema respiratorio (pulmones), el sudor, la saliva y la leche materna (41).

En situaciones de deterioro de la función renal la excreción disminuye, por lo que habrán de prescribirse dosis menores. Se deberá medir la función renal (usando la creatinina como parámetro) en pacientes ancianos (42).

\section{Farmacodinámica}

La farmacodinámica se ocupa del estudio de los mecanismos de acción de los fármacos, así como de los efectos que estos ocasionan. Los mecanismos de acción de los psicofármacos (enzimáticos, sobre moléculas transportadoras, sobre canales iónicos y sobre receptores) fueron ampliamente descriptos precedentemente en este artículo (véase "Dianas de la acción psicofarmacológica"). No obstante, la tabla 6 presenta algunos ejemplos de recordatorio $(10,41,42)$.

\section{TABLA 6. MECANISMOS DE ACCIÓN DE LOS PSICOFÁRMACOS}

\begin{tabular}{|c|l|}
\hline $\begin{array}{c}\text { Acción agonista } \\
\text { sobre el receptor }\end{array}$ & $\begin{array}{l}\text { Las benzodiazepinas se unen a los receptores GABA-A del GABA, facilitando la } \\
\text { apertura de canales de } \mathrm{Cl}^{-} \text {(modulación alostérica positiva). }\end{array}$ \\
\hline $\begin{array}{c}\text { Acción antagonista } \\
\text { sobre el receptor }\end{array}$ & $\begin{array}{l}\text { Los antipsicóticos típicos ejercen una acción antagonista sobre los receptores } \\
\text { dopaminérgicos a nivel del sistema mesolímbico (lo cual explica sus efectos } \\
\text { terapéuticos), pero también a nivel nigroestriatal, produciendo efectos adversos } \\
\text { extrapiramidales. }\end{array}$ \\
\hline
\end{tabular}




\begin{tabular}{|c|l|}
\hline $\begin{array}{c}\text { Acción sobre } \\
\text { segundos mensajeros }\end{array}$ & $\begin{array}{l}\text { El litio, por ejemplo, inhibe el metabolismo del inositol fosfato, el cual actúa } \\
\text { como segundo mensajero en la neurotransmisión. }\end{array}$ \\
\hline $\begin{array}{c}\text { Alteración del almace- } \\
\text { namiento vesicular }\end{array}$ & $\begin{array}{l}\text { La reserpina impide que los neurotransmisores se incorporen a las vesículas de } \\
\text { almacenamiento en el terminal presináptico neuronal. }\end{array}$ \\
\hline $\begin{array}{c}\text { Aumento de la } \\
\text { liberación del neuro- } \\
\text { transmisor }\end{array}$ & $\begin{array}{l}\text { Las anfetaminas aumentan la liberación presináptica de noradrenalina y dopa- } \\
\text { mina. }\end{array}$ \\
\hline $\begin{array}{c}\text { Inhibición de la } \\
\text { recaptación del } \\
\text { neurotransmisor }\end{array}$ & $\begin{array}{l}\text { La mayoría de los antidepresivos ejerce su acción impidiendo la recaptación de } \\
\text { monoaminas en el terminal presináptico, con el consecuente aumento de las } \\
\text { mismas en la hendidura sináptica. }\end{array}$ \\
\hline $\begin{array}{c}\text { Inhibición } \\
\text { enzimática }\end{array}$ & $\begin{array}{l}\text { Los antidepresivos IMAO clásicos inhiben de forma irreversible la enzima mono- } \\
\text { amino-oxidasa, impidiendo la oxidación de neurotransmisores monoaminérgi- } \\
\text { cos. }\end{array}$ \\
\hline
\end{tabular}

Algunos autores añaden a lo descripto en la tabla 6, lo que se denomina "mecanismos inespecíficos" de los psicofármacos, que se refieren a acciones farmacológicas sobre amplias estructuras biológicas, cuya función se modifica a profundidad (por ejemplo, modificación de la fluidez de las membranas celulares, creación de barreras físicas, alteraciones del pH, entre otros) (45).

En lo que respecta a los efectos ocasionados por los psicofármacos, éstos pueden ser de dos tipos (41):

- Terapéuticos o primarios: Cuando se obtiene el efecto clínico o preventivo que justificó su uso; o,

- No deseados, secundarios o colaterales: En donde se encuentran las reacciones adversas.

En muchas circunstancias, ambos de tipos de efectos están íntimamente conectados; más aún, en algunos casos es imposible delimitarlos e incluso en otras ocasiones se ha considerado que los efectos secundarios eran un buen marcador de eficacia terapéutica (como en el caso de los efectos extrapiramidales de los antipsicóticos típicos).

Aquí cabe mencionar el concepto de índice terapéutico. Éste es una medida relativa de la toxicidad o inocuidad de un fármaco. Se define como la proporción de la mediana de la dosis tóxica ( $\mathrm{DT}_{50}$, dosis a la cual el $50 \%$ de las personas experimenta efectos tóxicos) por la mediana de la dosis eficaz ( $\mathrm{DE}_{50}$, dosis a la cual el $50 \%$ de las personas experimenta efectos terapéuticos). Por ejemplo, el haloperidol tiene un índice terapéutico elevado, que se pone de manifiesto por el amplio margen de dosis a las que se prescribe sin necesidad de vigilar su concentración plasmática. Por el contrario, el litio tiene un índice terapéutico bajo, por lo que se hace mandatorio vigilar de cerca su concentración plasmática a fin de prevenir la aparición de efectos tóxicos (21). 


\section{Interacciones medicamentosas}

Uno de los factores que más puede influenciar el efecto de los psicofármacos es la interacción medicamentosa. Ésta se entiende como el cambio en los efectos de un fármaco por la presencia de otro fármaco, alimento, bebida o agente químico ambiental. El resultado puede ser un aumento o una reducción del efecto terapéutico del fármaco y/o la presencia de efectos secundarios y/o tóxicos deletéreos. La tasa de incidencia de interacciones medicamentosas, según algunas series, puede llegar al $8,8 \%(48,49)$.

Las interacciones medicamentosas pueden ser:

- Farmacocinéticas: Las interacciones farmacocinéticas son aquellas que pueden afectar a cualquiera de los procesos LADME (véase el detalle de estos procesos más arriba en este artículo). El resultado es un retraso en el inicio de acción del fármaco, disminución o aumento de su efecto, intoxicación o alteración de la excreción, con el consiguiente efecto en la concentración del fármaco en el lugar de acción; y,

- Farmacodinámicas: Aquellas que ocurren cuando dos o más fármacos actúan sobre los mismos objetivos moleculares, produciéndose un efecto aditivo o sinérgico, o bien antagónico.

Ejemplos de interacciones medicamentosas farmacocinéticas ya se han expuesto en este artículo, en el apartado relativo al metabolismo de los fármacos y a la función del sistema enzimático del citocromo P450.

Las interacciones medicamentosas entre fármacos (interacciones farmacodinámicas) que generen cambios bioquímicos aditivos pueden favorecer la aparición de efectos tóxicos. Por ejemplo, cuando los inhibidores de la monoamino-oxidasa se administran a la vez que antidepresivos tricíclicos o inhibidores selectivos de la recaptación de serotonina, pueden desencadenar un síndrome serotoninérgico (34), en el cual la serotonina acumulada en exceso provoca un cuadro potencialmente mortal caracterizado por una tríada de alteraciones del estado mental, disfunción autonómica y anomalías musculares. Con el progreso del síndrome pueden aparecer hipertonía, rabdomiólisis e insuficiencia renal.

Existe un sinnúmero de interacciones medicamentosas significativas para la práctica clínica, que van más allá de los objetivos de este artículo. No obstante, se insiste al lector a verificar los tipos de interacciones existentes al prescribir un fármaco. Esta verificación puede hacerse a través de los prospectos que acompañan a los fármacos o consultando literatura especializada sobre el tema.

\section{Clasificación de los psicofármacos}

A efectos prácticos, los psicofármacos se clasifican según lo expuesto en la tabla 7. 


\begin{tabular}{|c|c|}
\hline \multicolumn{2}{|r|}{ TABLA 7. CLASIFICACIÓN DE LOS PSICOFÁRMACOS } \\
\hline $\begin{array}{l}\text { Inhibidores de la } \\
\text { acetilcolinesterasa }\end{array}$ & Donepezilo; Rivastigmina; Galantamina. \\
\hline $\begin{array}{c}\text { Antagonistas de los re- } \\
\text { ceptores colinérgicos } \\
\text { muscarínicos }\end{array}$ & Biperideno. \\
\hline $\begin{array}{l}\text { Agonistas y antagonistas } \\
\text { adrenérgicos }\end{array}$ & $\begin{array}{l}\text { Propranolol; Clonidina; Dextroanfetamina; Metilfenidato; Dexmetilfenidato; } \\
\text { Modafinilo. }\end{array}$ \\
\hline Estabilizantes del ánimo & $\begin{array}{l}\text { Litio; Valproato; Carbamazepina; Topiramato; Lamotrigina; Gapentina; Pregaba- } \\
\text { lina. }\end{array}$ \\
\hline $\begin{array}{l}\text { Agonistas parciales del } \\
\text { receptor } 5 \mathrm{HT}_{1 \mathrm{~A}}\end{array}$ & Buspirona. \\
\hline $\begin{array}{l}\text { Agonistas del receptor de } \\
\text { benzodiazepinas }\end{array}$ & $\begin{array}{l}\text { Benzodiazepinas (Midazolam; Triazolam; Alprazolam; Flunitrazepam; Lorazepam; } \\
\text { Diazepam; Clonazepam); Fármacos Z (zolpidem, eszopiclona). }\end{array}$ \\
\hline Barbitúricos & Fenobarbital. \\
\hline $\begin{array}{l}\text { Antagonistas del recep- } \\
\text { tor de dopamina. Anti- } \\
\text { psicóticos de primera } \\
\text { generación, clásicos o } \\
\text { típicos. }\end{array}$ & Clorpromazina; Levomepromazina; Tioridazina; Pimozida; Haloperidol; Loxapina. \\
\hline $\begin{array}{l}\text { Antagonistas de dopami- } \\
\text { na-serotonina. Antipsicó- } \\
\text { ticos de segunda genera- } \\
\text { ción o atípicos. }\end{array}$ & Risperidona; Olanzapina; Quetiapina; Aripiprazol; Paliperidona; Clozapina. \\
\hline $\begin{array}{l}\text { Antipsicóticos } \\
\text { de depósito }\end{array}$ & Decanoato de haloperidol; Palmitato de pipotiazina. \\
\hline $\begin{array}{l}\text { Antagonistas glutama- } \\
\text { térgicos (NMDA) }\end{array}$ & Memantina. \\
\hline $\begin{array}{l}\text { Antagonistas histaminér- } \\
\text { gicos no selectivos. }\end{array}$ & Difenhidramina; Hidroxicina; Prometazina. \\
\hline $\begin{array}{l}\text { Inhibidores de la recap- } \\
\text { tación/antagonistas de } \\
\text { serotonina }\end{array}$ & Trazodona. \\
\hline $\begin{array}{l}\text { Inhibidores de la recap- } \\
\text { tación de dopamina- } \\
\text { noradrenalina }\end{array}$ & Bupropión. \\
\hline $\begin{array}{l}\text { Inhibidores de la recap- } \\
\text { tación de noradrenalina }\end{array}$ & Atomoxetina; Reboxetina. \\
\hline
\end{tabular}




\begin{tabular}{|c|c|}
\hline $\begin{array}{l}\text { Inhibidores de la recap- } \\
\text { tación de serotonina- } \\
\text { noradrenalina }\end{array}$ & Duloxetina; Venlafaxina; Desvenlafaxina; Milnacipran; Levomilnacipran. \\
\hline $\begin{array}{l}\text { Inhibidores selectivos de } \\
\text { la recaptación de seroto- } \\
\text { nina }\end{array}$ & Citalopram; Escitalopram; Fluoxetina; Fluvoxamina; Paroxetina; Sertralina. \\
\hline $\begin{array}{l}\text { Antidepresivos noradre- } \\
\text { nérgicos y serotoninérgi- } \\
\text { cos específicos }\end{array}$ & Mirtazapina. \\
\hline $\begin{array}{c}\text { Antidepresivos tricíclicos } \\
\text { y tetracíclicos }\end{array}$ & Imipramina; Amitriptilina; Clomipramina; Nortriptilina; Maprotilina. \\
\hline $\begin{array}{l}\text { Agonistas de los recepto- } \\
\text { res de melatonina }\end{array}$ & Agomelatina; Melatonina. \\
\hline Multimodal & Vortioxetina. \\
\hline $\begin{array}{c}\text { Agonista par- } \\
\text { cial/inhibidor de la re- } \\
\text { captación de la serotoni- } \\
\text { na }\end{array}$ & Vilazodona. \\
\hline
\end{tabular}

\section{Selección de un fármaco}

Ningún psicofármaco es siempre eficaz en todos los pacientes con el mismo diagnóstico. La eficacia de un fármaco solo puede predecirse en parte y depende de la farmacocinética y farmacodinámica del psicotrópico y del trípode biopsicosocial del paciente.

Por lo tanto, la selección de un fármaco determinado se hace caso por caso, siguiendo el juicio clínico, y en base a lo siguiente: 1 . El tipo de fármaco en cuestión; 2. La biología del paciente en particular; 3 . La experiencia y el juicio clínico del médico que prescribe el fármaco; y, 4. El contexto situacional y ambiental del paciente.

Asimismo, constituye un verdadero reto determinar la dosis óptima del fármaco con los mínimos efectos secundarios asociados, cuánto tiempo se debe mantener un tratamiento que ha sido eficaz y cuándo ha de retirarse uno que no ha sido efectivo (42); por ello, muchas veces, la evidencia y la experiencia van juntas a la hora de la toma de decisiones.

\section{PSICOFARMACOLOGÍA EN NIÑOS Y ADOLESCENTES}

En los últimos años, el uso de psicofármacos en psiquiatría de la infancia y la adolescencia ha crecido considerablemente. Desde el descubrimiento fortuito de los efectos de las anfetaminas en la hiperactividad infantil (Charles Bradley, 1937) hasta los ensayos clínicos multicéntricos de la década de 2000, la psicofarmacología pediátrica se ha convertido gradualmente en un área activa de investigación y, al menos en algunos países, en parte de la práctica clínica del día a día. No obstante, la psicofarmacología en niños y adolescentes ha sido objeto de debate y controversia entre el público en general y entre los expertos en psiquiatría, pedia- 
tría y salud mental, especialmente en lo referente a la eficacia y seguridad del uso de psicotrópicos para el tratamiento de problemas emocionales y del comportamiento durante el desarrollo (físico y mental) (50).

Con la notable excepción de los fármacos desarrollados para el trastorno por déficit de atención e hiperactividad (TDAH), que se introdujeron originalmente para uso pediátrico y luego se aplicaron en adultos, los psicofármacos destinados al tratamiento de la depresión, la ansiedad, la manía, o la psicosis, se utilizaron primeramente en adultos y, a continuación, en niños afectados por estas condiciones (51). Es por esto último que muchos expertos han expresado su preocupación acerca de la validez de la aplicación de criterios diagnósticos de adultos a la población pediátrica, así como sobre la seguridad que tiene extrapolar resultados obtenidos en adultos en los niños (50).

Varios factores entran en juego a la hora de elegir un tratamiento psiquiátrico en población pediátrica. El primer paso, mandatorio, es una completa evaluación diagnóstica. Los pacientes con trastornos psicóticos o síntomas manifores, típicamente, se beneficiarán con farmacoterapia para controlar los síntomas y restaurar su funcionalidad. Pacientes con otros trastornos, por otra parte, podrían ser tratados exitosamente con intervenciones no farmacológicas. La utilización de psicofármacos, por lo tanto, es sólo una de las varias opciones existentes en psiquiatría pediátrica y sus riesgos y beneficios deben ser considerados por el médico tratante, la familia y, siempre que sea posible, por el niño o adolescente (Figura 1).

Figura 1. Aproximación general a la psicofarmacoterapia en pediatría (50).

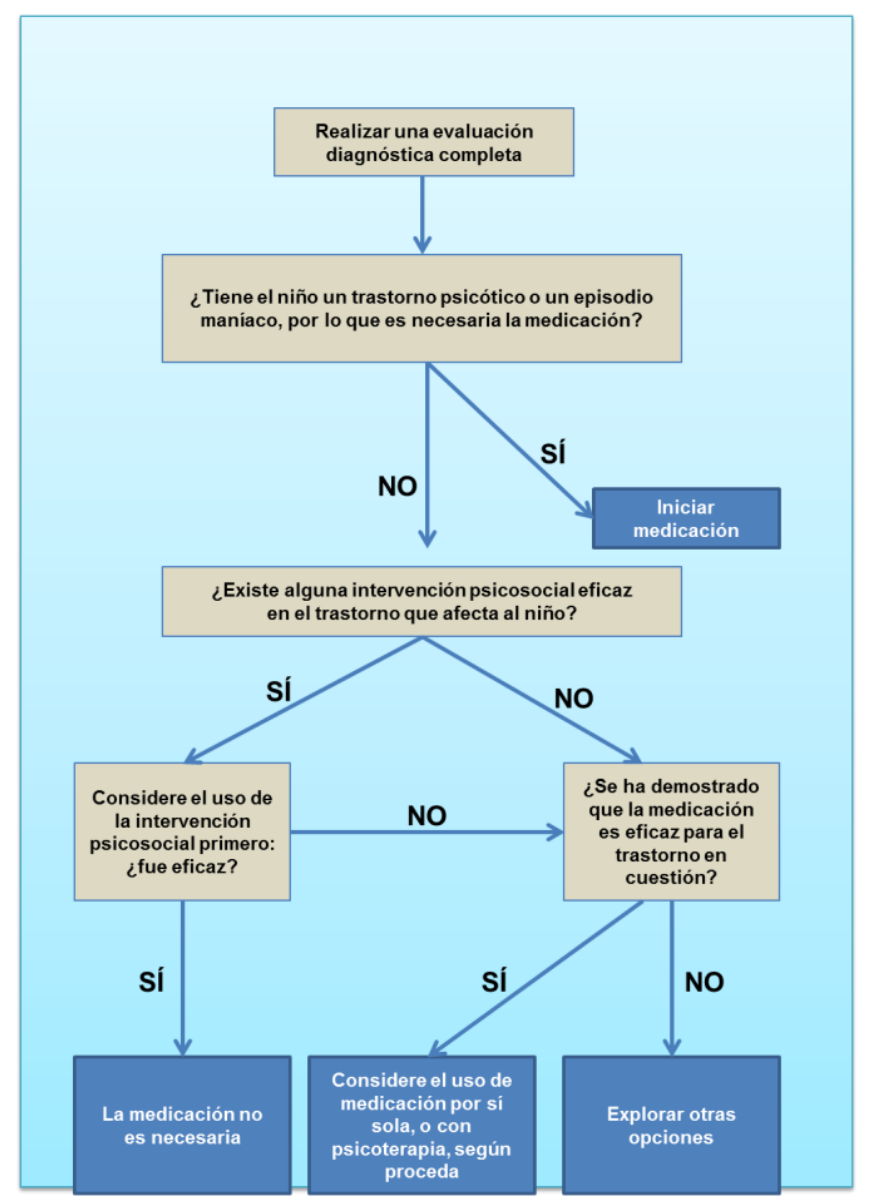




\section{Farmacocinética en el niño}

Existen algunas diferencias farmacocinéticas en niños y adolescentes respecto a los adultos que afectan al tratamiento, a saber (34):

1. La acidez en el estómago es menor en niños que en adultos. De esto depende la cantidad de fármaco ionizado, lo que influye en la absorción (en el niño se absorben más lentamente los estabilizantes del ánimo -no contando al litio-, estimulantes y algunos antidepresivos).

2. En el niño, la absorción oral puede ser errática, por lo que, si existen situaciones de riesgo vital o si se precisa controlar la cantidad de sustancia en sangre de forma estricta, puede ser preferible la vía intravenosa.

3. El volumen de agua extracelular está incrementado, con lo que para aquellos fármacos hidrófilos (por ejemplo, litio), las concentraciones pueden ser menores que las del adulto cuando se administra la dosis ajustada al peso (es de destacar que a lo largo del desarrollo, el agua extracelular decrece, y se incrementa la grasa corporal).

4. En los recién nacidos, la proporción de unión de los fármacos a las proteínas plasmáticas está disminuida (esto se equipara a la del adulto, al año de edad).

5. Las membranas celulares poseen una permeabilidad incrementada y, además, la barrera hematoencefálica no adquiere importancia hasta el primer año de vida.

6. En el recién nacido (e incluso hasta el año de vida), el metabolismo está enlentecido debido a una actividad reducida de los sistemas enzimáticos hepáticos; los niños mayores, hasta la pubertad, metabolizan algunos fármacos más rápido.

7. La función renal está disminuida al nacer y se regulariza durante el primer año de vida. En niños escolares y adolescentes, la eliminación renal está incrementada en comparación con los adultos, por lo que algunos fármacos pueden disminuir su concentración (por ejemplo, litio).

\section{Farmacodinámica en el niño}

La farmacodinámica del niño es compleja, y presenta variaciones a lo largo del desarrollo. Como se detalló previamente con respecto a los adultos, la mayoría de los psicotrópicos actúan sobre los sistemas de la dopamina, serotonina y noradrenalina, cuyos receptores atraviesan importantes cambios durante el proceso de desarrollo del niño $(52,53)$ : por ejemplo, la densidad de receptores alcanza un pico en la edad preescolar, para ir luego decreciendo hacia niveles similares a los del adulto en la adolescencia tardía. El impacto de estos cambios todavía no está completamente comprendido, aunque, como ejemplo, se ha visto que los tricíclicos (con probada acción en los adultos) no tienen efecto antidepresivo demostrable en los niños (54).

La acción específica de los psicofármacos en el tratamiento de trastornos mentales que afectan a la población pediátrica va más allá de los alcances de este artículo. No obstante, vale la 
pena adelantar que, en la práctica, conviene comenzar con una dosis pequeña e incrementarla cuando se observen efectos clínicos; sin embargo, el médico podría decidir utilizar dosis de adulto en los niños si fueran eficaces y los efectos adversos resultaran aceptables.

\section{PSICOFARMACOLOGÍA EN ADULTOS MAYORES}

El tratamiento farmacológico de los adultos mayores se ve complicado por diversos factores, entre los que se citan: 1 . Mayor sensibilidad a los efectos secundarios periféricos y centrales; 2. Cambios farmacocinéticos y farmacodinámicos; 3. Patología física concomitante; 4. Polifarmacia; 5. Disminución de las funciones cardiaca y cognitiva; 6 . Capacidad funcional disminuida; $y, 7$. Aspectos relacionados con el cumplimiento terapéutico (34).

\section{Farmacocinética en el adulto mayor}

En el adulto mayor, los principales cambios farmacocinéticos (y sus efectos) se exponen en la tabla $8(21,34)$.

\begin{tabular}{|c|c|c|}
\hline \multicolumn{3}{|c|}{ TABLA 8. FARMACOCINÉTICA EN EL ADULTO MAYOR } \\
\hline Fase & Cambio & Efecto \\
\hline Absorción & $\begin{array}{l}\text { Incremento del pH gástrico, disminución de } \\
\text { las vellosidades superficiales, disminución } \\
\text { de la motilidad gástrica, disminución de la } \\
\text { perfusión intestinal. }\end{array}$ & Se enlentece la absorción. \\
\hline Distribución & $\begin{array}{l}\text { Disminución del agua corporal total y la } \\
\text { masa corporal magra, aumento de la grasa } \\
\text { corporal total (más en mujeres), disminuye } \\
\text { la albúmina. }\end{array}$ & $\begin{array}{l}\text { El volumen de distribución au- } \\
\text { menta para los fármacos lipófilos } \\
\text { y disminuye para los hidrófilos. Se } \\
\text { incrementa el porcentaje de fár- } \\
\text { macos libres, al no estar fijados a } \\
\text { la albúmina. }\end{array}$ \\
\hline $\begin{array}{l}\text { Metabolismo } \\
\text { y excreción }\end{array}$ & $\begin{array}{l}\text { A nivel renal: disminución del torrente } \\
\text { circulatorio renal y la tasa de filtración } \\
\text { glomerular; a nivel hepático: disminución } \\
\text { de la actividad enzimática. }\end{array}$ & $\begin{array}{l}\text { Las semividas de los psicofárma- } \\
\text { cos se prolongan al disminuir el } \\
\text { metabolismo, si el volumen de } \\
\text { distribución sigue siendo el mis- } \\
\text { mo. }\end{array}$ \\
\hline
\end{tabular}

\section{Farmacodinámica en el adulto mayor}

Los pacientes adultos mayores, en general, son más sensibles a los efectos de los psicofármacos, quizá debido a cambios en los sistemas de neurotransmisores o en la sensibilidad receptorial (34). Algunos cambios neurofisiológicos importantes en el adulto mayor son:

1. La degeneración del sistema colinérgico afecta la memoria y predispone a exacerbar el déficit cognitivo (por ejemplo, con anticolinérgicos); la alteración de la memoria y la sedación pueden verse incrementadas por el uso de benzodiazepinas o hipnóticos. 
2. La degeneración de la vía nigroestriatal y el descenso de la dopamina están relacionados con una mayor sensibilidad del paciente anciano a los efectos extrapiramidales al administrar antipsicóticos.

3. Los antidepresivos tricíclicos afectan la conducción cardiaca en mayor grado en adultos mayores con enfermedad cardiaca y los neurolépticos en personas con enfermedad de Parkinson y enfermedad por cuerpos de Lewy.

En los adultos mayores es de destacar que la indicación de diferentes grupos de psicofármacos sería igual que en los adultos más jóvenes, atendiendo a la incidencia de efectos secundarios e interacciones farmacológicas. Asimismo, se recalca que, en la práctica usual, el tratamiento se inicia con dosis bajas, típicamente en torno a la mitad de la dosis de los adultos más jóvenes, que luego se elevará con incrementos pequeños, lentamente.

\section{PSICOFARMACOLOGÍA EN MUJERES EMBARAZADAS}

Los médicos que tuvieran que recetar psicotrópicos durante el embarazo deben sopesar los riesgos conocidos o la falta de información sobre los riesgos que conlleva el tratamiento en este grupo particularmente vulnerable (55). Una regla básica sería no administrar ningún fármaco a una mujer embarazada (en particular en el primer trimestre) o que esté amamantando a su hijo, a menos que su trastorno mental sea grave (21).

Debido a la posibilidad de que se produzcan efectos nocivos sobre el feto y sobre la madre, ante la administración de psicotrópicos en el embarazo la indicación de cualquier tratamiento deberá ser consensuada entre la paciente, la familia y el médico tratante (56). A modo de información, los psicofármacos más teratogénicos son el valproato, la carbamazepina y, en menor grado, el litio.

En cuanto a la elección de la medicación, se debe tener en cuenta la clasificación de la FDA de los Estados Unidos de América, en la que se señala el riesgo potencial de los distintos fármacos que atraviesan la placenta de provocar defectos postnatales. Se clasificad en A, B, C, D y X (de menor a mayor riesgo), a saber (55):

- Grupo A: Los estudios controlados no muestran riesgos en seres humanos.

- Grupo B: No hay evidencia de riesgo en seres humanos, pero no se han realizado estudios adecuados en humanos. Pertenecen a este grupo los inhibidores selectivos de la recaptación de serotonina y antipsicóticos atípicos (B/C).

- Grupo C: El riesgo no puede ser calculado. Hay evidencias de teratogenicidad en animales, pero no existen estudios controlados en mujeres o no están disponibles. Pertenecen a este grupo la buspirona, los antipsicóticos típicos y atípicos $(\mathrm{B} / \mathrm{C})$ y los antidepresivos tricíclicos (C/D).

- Grupo D: Existen evidencias de riesgo en seres humanos. Aquí se encuentran el litio, valproato, carbamazepina y algunos antidepresivos tricíclicos. 
- Grupo X: Riesgo de teratogenicidad. Pertenecen a este grupo las benzodiazepinas hipnóticas.

En el caso de la administración de psicofármacos durante el parto, o poco antes, se pueden provocar sedación y depresión respiratoria neonatales, lo que posiblemente requerirá de ventilación mecánica, o la dependencia física del fármaco, que requerirá tratamiento de desintoxicación y manejo del síndrome de abstinencia. Por último, se recalca que prácticamente todos los fármacos psicotrópicos se secretan en la leche materna $(21,34,55)$.

\section{PSICOFARMACOLOGÍA EN PACIENTES CON ENFERMEDAD RENAL O HEPÁTICA}

Finalmente, y si bien todas las enfermedades médicas pueden influir en la farmacocinética y en la farmacodinámica de todos los psicofármacos, son la insuficiencia renal y la insuficiencia hepática las que afectan profundamente estos procesos (principalmente, el metabolismo y la excreción). Es deber del médico tratante ser consciente de esta realidad, para poder realizar los ajustes requeridos para cada paciente en particular. A modo de resumen, la tabla 9 presenta la determinación de las dosis de psicofármacos en la insuficiencia hepática y renal $(19,45,56)$.

\begin{tabular}{|c|c|c|}
\hline \multicolumn{3}{|c|}{ TABLA 9. PSICOFÁRMACOS EN INSUFICIENCIA HEPÁTICA Y RENAL } \\
\hline Psicofármaco & Insuficiencia hepática & Insuficiencia renal \\
\hline Alprazolam & $\begin{array}{l}\text { Evitar en casos graves; riesgo de encefa- } \\
\text { lopatía }\end{array}$ & \\
\hline Amitriptilina & Reducir dosis & No requiere ajuste \\
\hline Aripiprazol & Utilizar con precaución & No requiere ajuste \\
\hline Bupropión & Disminuir dosis & Disminuir dosis \\
\hline Buspirona & $\begin{array}{l}\text { Reducir dosis; no se recomienda } \\
\text { en casos graves }\end{array}$ & $\begin{array}{l}\text { Reducir dosis; no se recomienda } \\
\text { en casos graves }\end{array}$ \\
\hline Carbamazepina & Monitorizar niveles & \\
\hline Citalopram & Disminuir dosis & Ajustar dosis \\
\hline Clorpromazina & Evitar por riesgo de encefalopatía & No requiere ajuste \\
\hline Diazepam & $\begin{array}{l}\text { Reducir dosis en el 50\%; evitar en casos } \\
\text { graves por riesgo de encefalopatía }\end{array}$ & $\begin{array}{l}\text { Disminución del aclaramiento no renal de } \\
\text { su metabolito }\end{array}$ \\
\hline Donepezilo & Disminuir dosis & No requiere ajuste \\
\hline Duloxetina & No emplear en insuficiencia hepática & No emplear en patología renal terminal \\
\hline Escitalopram & Disminuir dosis en $50 \%$ & Precaución en casos graves \\
\hline
\end{tabular}




\begin{tabular}{|c|c|c|}
\hline Fenitoína & Monitorizar niveles & $\begin{array}{l}\text { Disminución de unión proteínas; aumento } \\
\text { de aclaramiento no renal }\end{array}$ \\
\hline Fenobarbital & Disminuir dosis & Prolongar intervalo entre dosis \\
\hline Fluoxetina & Disminuir dosis en $50 \%$ & Disminuir dosis \\
\hline Fluvoxamina & Disminuir dosis y prolongar el intervalo & No requiere ajuste \\
\hline Haloperidol & No requiere ajuste & \\
\hline Imipramina & Disminuir dosis & No requiere ajuste \\
\hline Litio & $\begin{array}{l}\text { Necesidad de incrementar dosis en pre- } \\
\text { sencia de ascitis }\end{array}$ & Ajustar dosis \\
\hline Lorazepam & $\begin{array}{l}\text { Riesgo de encefalopatía; dosis inicial de la } \\
\text { mitad si hay antecedentes de encefalopa- } \\
\text { tía }\end{array}$ & Ajustar dosis \\
\hline Memantina & No se recomienda en casos graves & En casos graves disminuir dosis en $50 \%$ \\
\hline Mirtazapina & Disminuir dosis & No requiere ajuste \\
\hline Nortriptilina & Disminuir dosis & No se afecta su semivida \\
\hline Olanzapina & No requiere ajuste & No requiere ajuste \\
\hline Paroxetina & Iniciar con dosis de 10 mg/día & \\
\hline Quetiapina & Disminuir dosis & No parece requerir ajuste \\
\hline Reboxetina & Disminuir dosis & Ajustar dosis \\
\hline Risperidona & Disminuir dosis & $\begin{array}{l}\text { Disminuir dosis por reducción se su acla- } \\
\text { ramiento en } 60 \%\end{array}$ \\
\hline Rivastigmina & No requiere ajuste & No requiere ajuste \\
\hline Sertralina & Disminuir dosis & No requiere ajuste \\
\hline Valproato & Disminuir dosis y monitorizar & $\begin{array}{l}\text { Disminución de su unión a proteínas } \\
\text { plasmáticas }\end{array}$ \\
\hline Venlafaxina & Disminuir dosis en $50 \%$ & Disminuir dosis en $25 \%$ o más \\
\hline Vortioxetina & No requiere ajuste si leve o moderada & No requiere ajuste \\
\hline
\end{tabular}

\section{A MODO DE CONCLUSIÓN: PROMESAS GENÉTICAS EN PSIQUIATRÍA}

Se han confirmado importantes evidencias, a partir de estudios en familias y en gemelos, acerca de que los genes tienen un rol significativo en la patogénesis de muchos trastornos psiquiátricos (57). Esto significa que importantes pistas de los mecanismos patogénicos de las enfermedades han permanecido escondidas dentro del genoma, pistas que podrán llevar al diseño de nuevos psicofármacos y nuevas terapias destinadas a corregir los procesos fisio- 
patológicos. Con pocas excepciones (por ejemplo, las raras formas monogénicas de autismo) la alta heredabilidad de los trastornos mentales es el resultado de efectos sumatorios, agregados, de un sinnúmero de genes, tal vez cientos, cada uno de los cuales contribuye solo con un pequeño incremento del riesgo. Asimismo, la mayoría de los casos de autismo, y esencialmente todos los casos de esquizofrenia y trastorno bipolar, serían poligénicos (58). Tomando en cuenta la gran cantidad de variaciones en la secuencia del ADN que caracterizan al genoma humano (59), es muy fácil encontrar variantes en la secuencia, pero es extremadamente difícil determinar si una variante en particular tiene influencia en el riesgo de desarrollar una enfermedad.

En los últimos 10 años ha existido un destacado avance en la secuenciación del ADN, reduciéndose su costo aproximadamente en un millón de veces, mientras que han aumentado exponencialmente su velocidad y precisión. Como resultado de todo esto se ha pasado de ningún locus conocido asociado a la esquizofrenia en 2007 a más de 100 loci con significancia en 2013. A medida que las muestras son tomadas de poblaciones más grandes, el progreso en la "disección" genética de la esquizofrenia, el trastorno bipolar y el autismo se está acelerando (60).

El análisis genético de la esquizofrenia, el trastorno bipolar y el autismo ha comenzado a identificar complejos de múltiples subunidades proteicas y redes de proteínas implicadas en la patogénesis de alteraciones postsinápticas en las sinapsis excitadoras (autismo y esquizofrenia) $y$, también, canales de $\mathrm{Ca}^{+2}$ de tipo $\mathrm{L}$, en el que los genes que codifican cuatro diferentes subunidades han sido identificados como asociados con el trastorno bipolar o la esquizofrenia (61). Otras proteínas, previamente insospechadas, han sido también identificadas por estudios genéticos, por ejemplo: la mutación del gen SCN2A, que codifica la subunidad $\alpha$ del canal de $\mathrm{Na}^{+}$tipo II es un gen de riesgo para el autismo (62).

Asimismo, en enero de 2016, se ha dado un paso esperanzador. Un equipo encabezado por el profesor Steve McCarroll, de la Facultad de Medicina de Harvard, ha logrado identificar el mayor riesgo genético para el desarrollo de la esquizofrenia: diversos alelos estructuralmente diversos de los componentes del complemento 4 (C4A, C4B). Estos alelos tienen diferentes niveles de expresión cerebral, con mayor cantidad de C4A en la esquizofrenia. La proteína C4 humana está localizada principalmente en las sinapsis neuronales, dendritas, axones y somas neuronales.

Las variaciones del gen C4 podrían precipitar una excesiva eliminación de sinapsis neuronales en el cerebro del adolescente, que está aún madurando su infraestructura de comunicación. La actividad excesiva del complemento en el cerebro jugaría un papel en el desarrollo de la esquizofrenia, al explicar los números reducidos de sinapsis neuronales encontradas en el cerebro de personas con esquizofrenia.

Normalmente, la eliminación de sinapsis neuronales ("pruning", en inglés) se deshace de aquellas conexiones que el cerebro humano ya no necesita, garantizando que el cerebro funcione de manera óptima. No obstante, una excesiva eliminación puede alterar la función mental. Esto podría explicar la razón por la cual los síntomas de la esquizofrenia se inician en la adolescencia tardía o adultez temprana y el porqué de la disminución del tejido de trabajo cerebral. Las intervenciones, genéticas o psicofarmacológicas, que pongan un freno al exce- 
sivo proceso de eliminación sináptica serían transformadoras y pivotantes en la prevención y tratamiento temprano de la enfermedad (63).

En otro orden de cosas, la información genética también contribuirá a la deconstrucción de las "quimeras" que actualmente pululan en el sistema de clasificación de la 5.a edición del Manual Diagnóstico y Estadístico de los Trastornos Mentales de la Asociación Americana de Psiquiatría (DSM-5) y a lograr mejores esquemas diagnósticos (64).

La contribución de la genética a lograr mejores diagnósticos no será rápida. Esto refleja, en parte, la necesidad de obtener datos genéticos razonablemente completos en múltiples poblaciones humanas, a fin de evitar falsos negativos. Más importante, se ha evidenciado que los trastornos psiquiátricos comparten factores de riesgo genéticos (por ejemplo, el riesgo de esquizofrenia conferido por variantes genéticas comunes es compartido en un $70 \%$ con el trastorno bipolar) (64). Hasta mutaciones genéticas, como delecciones de genes, duplicaciones, y translocaciones que se esperarían que actúen de una manera "mendeliana", pueden producir fenotipos de enfermedad múltiples, hasta en las mismas familias, o no producir enfermedad alguna, dependiendo de las interacciones con otros genes, efectos epigenéticos e influencias ambientales (65).

Todavía deberá pasar un cierto tiempo antes que la información genética sea utilizada para mejorar los diagnósticos clínicos; no obstante, la misma ya puede aportar importantes hipótesis acerca de los fenotipos intermedios (por ejemplo, que pueden generarse por anormalidades de los canales iónicos o las sinapsis excitadoras), así como de biomarcadores de respuesta al tratamiento (57).

Concluyendo, se puede afirmar que los trastornos psiquiátricos de los que se ocupa la psicofarmacología tendrán desafíos más grandes que enfrentar que aquellos de cualquier otra área de la medicina. Las dificultades inherentes a la poligenicidad, la heterogeneidad de la enfermedad, y las limitaciones de los modelos biológicos de estudio actual en psiquiatría constituyen ejemplos de estas dificultades. No obstante, el ritmo de desarrollo de la neurogenética y la neuropsicofarmacología se está acelerando, lo que brinda aires de esperanza para la pronta consecución de nuevas herramientas terapéuticas para hacer frente a estos desafíos.

\section{CONFLICTOS DE INTERÉS Y FUENTE DE FINANCIACIÓN}

Los autores declaran no poseer conflictos de interés. Fuente de financiación: ninguna.

\section{REFERENCIAS BIBLIOGRÁFICAS}

1. Torales J, Arce A, Zacarías M, Girala N, Moreno M, Szwako A, et al, autores. La Guía TAZ de Psicofarmacología Clínica. 1a ed. Asunción: EFACIM; 2014.

2. Girala Salomón N, Torales Benítez J, Bogado JA, Ortiz MB, Capurro MH. Introducción a la psicofarmacología. En: Arce Ramírez A, Torales Benítez J, editores. El Libro Azul de la Psiquiatría. 1a ed. Asunción: EFACIM; 2012. p. 57-78.

3. Collins $P$, Patel V, Joestl S, March D, Insel Th, Daar S. Grand challenges in global mental health. Nature. 2011; 475(7354):27-30. http://dx.doi.org/10.1038/475027a 
4. World Health Organization. The Global Burden of Disease: 2004 Update. Geneva. World Health Organization, 2008.

5. World Health Organization. Atlas on Substance Use. Geneva. World Health Organization, 2010.

6. Harrison PJ, Baldwin DS, Barnes TRE, Burns T, Ebmeier KP, Ferrier IN, et al. No psychiatry without psychopharmacology. $\mathrm{Br} J$ Psychiatry. 2011; 199(4): 263-265. http://dx.doi.org/10.1192/bjp.bp.111.094334

7. Gómez B, Salgueiro MC. Terapia cognitiva y medicación: un dilema en la trinchera. Revista Argentina de Clínica Psicológica. 2007; 16(3): 205-218. URL.

8. Preston J, Johnson J. Clinical psychopharmacology made ridiculously simple. 8a ed. Sacramento: MedMaster; 2014.

9. Torres Bares C, Escarabajal Arrieta MD. Psicofarmacología: una aproximación histórica. Anales de Psicología. 2005; 21(2): 199-212. URL.

10. García Valero MJ. Introducción a la psicofarmacología. En: Espert Tortajada R, editor. Máster en Psicofarmacología. 1a ed. Valencia: Alfa Delta Digital S.L.; 2015. p. 1-62.

11. Eguíluz I. Historia de la psicofarmacología. En: Salazar M, Peralta C, Pastor FJ, editores. Tratado de psicofarmacología. Bases y aplicación clínica. 2a ed. Madrid: Editorial Médica Panamericana; 2010. p. 3-13.

12. Martínez-Pérez J. Nuevas respuestas a una conducta desviada: sobre los fármacos en el tratamiento de la locura durante el siglo XIX. En: López-Muñoz F, Álamo C, editores. Historia de la Neuropsicofarmacología. 1a ed. Madrid: Ediciones Eurobook; 1998. p. 51-77.

13. Barona JL. Institutos de investigación, utopía científica y reduccionismo epistemológico. En: Barcia D, editor. Historia de la Psicofarmacología. 1a ed. Madrid: You \& Us; 1998. p. 421-448.

14. Caldwell AE. History of psychopharmacology. En: Clark W, del Giudice J, editores. Principles of psychopharmacology. London: Academic Press; 1978. p. 9-40.

15. Medrano Albéniz J. Tendencias futuras en psicofarmacología. En: Salazar M, Peralta C, Pastor FJ, editores. Tratado de psicofarmacología. Bases y aplicación clínica. 2a ed. Madrid: Editorial Médica Panamericana; 2010. p. 14-24.

16. Salazar M, Peralta C, Pastor FJ, editores. Tratado de psicofarmacología. Bases y aplicación clínica. 2a ed. Madrid: Editorial Médica Panamericana; 2010.

17. López-Muñoz F, Álamo C, editores. Historia de la Neuropsicofarmacología. 1a ed. Madrid: Ediciones Eurobook; 1998.

18. Stahl S. Psicofarmacología esencial de Stahl. Bases neurocientíficas y aplicaciones prácticas. 4a ed. Madrid: Aula Médica; 2014.

19. Brunton LL, editor. Goodman \& Gilman's The Pharmacological Basis of Therapeutics. 12a ed. New York: McGraw-Hill; 2011.

20. Pinel J. Biopsicología. 1a ed. Madrid: Prentice Hall; 2003.

21. Sadock BJ, Sadock VA, Sussman N. Kaplan \& Sadock Manual de bolsillo de tratamiento psicofarmacológico. 5a ed. Barcelona: Wolters Kluwer-Lippincott Williams \& Wilkins; 2012.

22. Álamo González C, López-Muñoz F, Cuenca Fernández E. Principios básicos en neurobiología. En: Salazar M, Peralta C, Pastor FJ, editores. Tratado de psicofarmacología. Bases y aplicación clínica. 2a ed. Madrid: Editorial Médica Panamericana; 2010. p. 121-137. 
23. Newman ME, Lerer B. Neurotransmisores y segundos mensajeros. En: Gelder MG, López-Ibor JJ, Andreasen N, editores. Tratado de psiquiatría. Barcelona: Ars Médica; 2003.p. 226-237.

24. Suudhof TC. Neurotransmitter release. Handb Exp Pharmacol. 2008; 184:1-21. http://dx.doi.org/10.1007/978-3-540-74805-2 1

25. Hall J. Guyton and Hall Textbook of Medical Physiology. 13a ed. Jackson: Saunders; 2016.

26. Gómez-Chavarín M, Santos-Echeverría R, García-García M, Torner-Aguilar C, BáezSaldaña A. Desarrollo de la vía dopaminérgica nigroestriatal. Arch Neurocien (Mex) 2014; 19(2): 95-103. URL.

27. Flores-Soto ME, Segura-Torres JE. Estructura y función de los receptores acetilcolina de tipo muscarínico y nicotínico. Rev Mex Neuroci. 2005; 6(4): 315-326. URL.

28. Cortes-Romero C, Galindo F, Galicia-Isasmendi S, Flores A. GABA: ¿dualidad funcional? Transición durante el neurodesarrollo. Rev Neurol. 2011; 52(11): 665-675. URL.

29. Atlantic International University [Internet]. Honolulu. Atlantic International University; 2016 [acceso 09 de enero de 2016]. Amador Rodero EM. Molecular neurotransmitters. Disponible en: http://www.aiu.edu/publications/student/spanish/MolecularNeuro-Transmitters.html

30. Schwappach B. An overview of trafficking and assembly of neurotransmitter receptors and ion channels. Mol Membr Biol. 2008; 25(4): 270-278. http://dx.doi.org/10.1080/09687680801960998

31. Universidad Javeriana [Internet]. Bogotá. Pontificia Universidad Javeriana; 2016 [acceso 09 de enero de 2016]. Neurobioquímica. Receptores. Disponible en: http://www.javeriana.edu.co/Facultades/Ciencias/neurobioquimica/libros/neuro bioquimica/receptores.html

32. Luján R. Bases moleculares de la señalización neuronal. Ciencia al Día Internacional 2004; 5(2): 1-19. URL.

33. Knopman D. Pharmacotherapy for Alzheimer's disease. Clin Neuropharmacol. 2003; 26: 93-101. URL.

34. Salazar M, Peralta C, Pastor FJ. Manual de Psicofarmacología. 2a ed. Madrid: Editorial Médica Panamericana; 2011.

35. Lin Z, Canales JJ, Björgvinsson T, Thomsen M, Qu H, Liu Q-R, et al. Monoamine Transporters: Vulnerable and Vital Doorkeepers. En: Rahman S, editor. Progress in Molecular Biology and Translational Science. Academic Press; 2011. p. 1-46. http://dx.doi.org/10.1016/B978-0-12-385506-0.00001-6

36. Hansson SR, Hoffman BJ, Mezey E. Ontogeny of vesicular monoamine transporter mRNAs VMAT1 and VMAT2. I. The developing rat central nervous system. Brain Res Dev Brain Res. 1998; 110(1): 135-158. http://dx.doi.org/10.1016/S01653806(98)00104-7

37. Filmore D. It's a GPCR world. Modern Drug Discovery 2004; 7(11): 24-28. URL.

38. Nestler EJ, Hyman SE, Malenka RC. Molecular neuropharmacology: a foundation for clinical neuroscience. 2a ed. New York: McGraw-Hill Medical; 2009.

39. Osorio JH. Citocromo P450 $2 \mathrm{A6}$ humano y su relación con el consumo de tabaco. Biosalud. 2010; 9(1): 36-46. URL. 
40. Collingridge GL, Olsen RW, Peters J, Spedding M. A nomenclature for ligand-gated ion channels. Neuropharmacology 2009; 56(1): 2-5. http://dx.doi.org/10.1016/i.neuropharm.2008.06.063

41. Álamo González C, López-Muñoz F, Cuenca Fernández E. Principios básicos en neuropsicofarmacología. En: Salazar M, Peralta C, Pastor FJ, editores. Tratado de psicofarmacología. Bases y aplicación clínica. 2a ed. Madrid: Editorial Médica Panamericana; 2010. p. 138-153.

42. Peregrín E, Albillo D. Principios del tratamiento con psicofármacos. En: Bravo MF, Saiz J, Bobes J, editores. Manual del Residente en Psiquiatría. Tomo II. 1a ed. Madrid: ENE Life Publicidad; 2009. p. 585-593.

43. Lin JH. Pharmacokinetic and pharmacodynamic variability: A daunting challenge in drug therapy. Curr Drug Metab. 2007; 8(2): 109-136. http://dx.doi.org/10.2174/138920007779816002

44. Colegio Oficial de Farmacéuticos de Segovia [Internet]. Segovia. Curso de Psicofarmacología; 2016 [acceso 13 de enero de 2016]. Ferrandis Tébar V. Farmacocinética y farmacodinamia. Disponible en: http://cofsegovia.portalfarma.com/Documentos/Curso\%20Fisioterap\%C3\%A9utas/2. -\%20Farmacocin\%C3\%A9tica\%20y\%20Farmacodinamia.pdf

45. Flórez J, Armijo J, Mediavilla A. Farmacología humana. 6a ed. Barcelona: Elsevier; 2013.

46. Sadock BJ, Sadock VA, Ruiz P. Kaplan \& Sadock Sinopsis de Psiquiatría. 11a ed. Barcelona: Wolters Kluwer; 2015.

47. Torales Benítez J, Rodríguez Marín H, López Olmedo P, Recalde Berni S. Esquizofrenia y otros trastornos psicóticos. En: Arce Ramírez A, Torales Benítez J, editores. El Libro Azul de la Psiquiatría. 1a ed. Asunción: EFACIM; 2012. p. 107-128.

48. Ruiz Fernández V. Interacciones medicamentosas. En: Salazar M, Peralta C, Pastor FJ, editores. Tratado de psicofarmacología. Bases y aplicación clínica. 2a ed. Madrid: Editorial Médica Panamericana; 2010. p. 88-102.

49. Robert RR. Drug-drug interactions associated with second-generation antipsychotics: considerations for clinicians and patients. Psychopharmacol Bull. 2007; 40(1): 77-97. URL.

50. Vitiello B. Principles in using psychotropic medication in children and adolescents. En: Rey JM, editor. IACAPAP e-Textbook of Child and Adolescent Mental Health. 1a ed. Geneva: International Association for Child and Adolescent Psychiatry and Allied Professions; 2012. p. 1-21.

51. Vitiello B. An international perspective on pediatric psychopharmacology. Int Rev Psychiatry. 2008; 20(2): 121-126. http://dx.doi.org/10.1080/09540260801887710

52. Mardomingo Sanz MJ, Cantó Díez TJ. Principios básicos de psicofarmacología pediátrica. En: Soutullo Esperón C, Mardomingo Sanz MJ, editores. Manual de Psiquiatría del niño y del adolescente. 1a ed. Madrid: Editorial Médica Panamericana; 2010. p. 339-364.

53. Rho JM, Storey TW. Molecular ontogeny of major neurotransmitter receptor systems in the mammalian central nervous system: norepinephrine, dopamine, serotonin, acetylcholine, and glycine. J Child Neurol. 2001; 16(4): 271-279. https://doi.org/10.1177/088307380101600407 
54. Connor DF, Meltzer BM. Pediatric psychopharmacology fast facts. 1a ed. New York: WW Norton; 2005.

55. ACOG Practice Bulletin: Clinical management guidelines for obstetriciangynecologists. Use of psychiatric medications during pregnancy and lactation. Obstet Gynecol. 2008; 111(4): 1001-1020. https://doi.org/10.1097/AOG.0b013e31816fd910

56. Govantes Esteso C, Vázquez Souza MI, Oca Bravo L. Manejo de psicofármacos en situaciones vitales específicas. En: Salazar M, Peralta C, Pastor FJ, editores. Tratado de psicofarmacología. Bases y aplicación clínica. 2a ed. Madrid: Editorial Médica Panamericana; 2010. p. 243-254.

57. Hyman SE. Revitalizing Psychiatric Therapeutics. Neuropsychopharmacology. 2014; 39(1): 220-229. https://doi.org/10.1038/npp.2013.181

58. Sullivan PF, Daly MJ, O'Donovan M. Genetic architecture of psychiatric disorders: the emerging picture and its implications. Nat Rev Genet. 2012; 13(8): 537-551. https://doi.org/10.1038/nrg3240

59. 1000 Genomes Project Consortium An integrated map of genetic variation from 1,092 human genomes. Nature. 2012; 491(7422): 56-65. https://doi.org/10.1038/nature11632

60. Lee SH, DeCandia TR, Ripke S, Yang J, the Schizophrenia Psychiatric Genome-Wide Association Study Consortium (PGC-SCZ); International Schizophrenia Consortium (ISC), et al. Estimating the proportion of variation in susceptibility to schizophrenia captured by common SNPs. Nat Genet. 2012; 44(4):247-250. https://doi.org/10.1038/ng.1108

61. Cross-Disorder Group of the Psychiatric Genomics Consortium. Identification of risk loci with shared effects on five major psychiatric disorders: a genome-wide analysis. Lancet. 2013; 381(9875): 1371-1379. https://doi.org/10.1016/S01406736(12)62129-1

62. Neale BM1, Kou Y, Liu L, Ma'ayan A, Samocha KE, Sabo A, et al. Patterns and rates of exonic de novo mutations in autism spectrum disorders. Nature. 2012; 485(7397): 242-245. https://doi.org/10.1038/nature11011

63. Sekar A, Bialas A, de Rivera H, Davis A, Hammond TR, Kamitaki N, et al. Schizophrenia risk from complex variation of complement component 4 . Nature. 2016;530(7589):177-183. https://doi.org/10.1038/nature16549

64. Hyman SE. The diagnosis of mental disorders: the problem of reification. Annu Rev Clin 2010; Psychol. 6: 155-179. https://doi.org/10.1146/annurev.clinpsy.3.022806.091532

65. Sahoo T, Theisen A, Rosenfeld JA, Lamb AN, Ravnan JB, Schultz RA, et al. Copy number variants of schizophrenia susceptibility loci are associated with a spectrum of speech and developmental delays and behavior problems. Genet Med. 2011; 13(1): 868-880. https://doi.org/10.1097/GIM.0b013e3182217a06 